\title{
Time-Series Momentum in Nearly 100 Years of Stock Returns*
}

\author{
Bryan Y. Lim, Jiaguo (George) Wang*, Yaqiong $\mathrm{Yao}^{\S}$
}

September 2018

\begin{abstract}
We document strong time-series momentum effects in individual stocks in the US markets from 1927 to 2017 . Time-series momentum is not specific to sub-periods, firm sizes, formation- and holding-period lengths, or geographic markets. The effects persist after controlling for standard risk factors. Time-series momentum effects are conditional on the market state, the information discreteness of the constituent stocks and investor sentiment. We propose two alternative implementations, revised time-series momentum and dual momentum, which generate even higher profits than standard time-series momentum.
\end{abstract}

JEL classification: G11; G12

Keywords: Time-series stock momentum; Return predictability; Market efficiency

\footnotetext{
*We thank Geert Bekaert (the editor) and an anonymous referee for their comments, which have significantly improved the paper. Our gratitude extends to Amit Goyal, Bruce Grundy, Allaudeen Hameed, A lex Kostakis , Spencer Martin, Takeshi Yamada, Shaojun Zhang (AsianFA discussant), Dazhi Zheng (FMA discussant), and seminar participants at the Asian Finance Association 2016 Annual Meeting and the Financial Management Association 2016 Annual Meeting for their helpful comments. Part of the paper was completed while Jiaguo (George) Wang and Yaqiong Yao were visiting New York University in 2015. This paper supersedes our working paper previously circulated as "The Enduring Effect of Time-series Momentum on Stock Returns over Nearly 100 Years." We thank Voraphat Srichanachaichok and Ian D'Souza for their contribution to the earlier drafts of this paper. All remaining errors are ours.

$\dagger$ Department of Finance, University of Melbourne, VIC 3010, Australia; email: blim@unimelb.edu.au.

* Department of Accounting and Finance, Lancaster University Management School, LA 1 4YX, United Kingdom; email: george.wang@lancaster.ac.uk.

$\S$ Corresponding Author: Department of Accounting and Finance, Lancaster University Management School, LA1 4YX, United Kingdom; email: yaqiong.yao@lancaster.ac.uk, Tel: (+44) 01524510731.
} 


\section{Introduction}

Moskowitz, Ooi and Pedersen (2012) were the first to document that a strategy that buys futures contracts with positive prior-year returns and sells futures contracts with negative prior-year returns can generate significant profits. They termed this "time-series momentum" to distinguish it from more traditional cross-sectional momentum, in which the sign of the position in a given asset is determined by the rank of its prior returns relative to those of other assets. The literature on time-series momentum has focused on its presence across asset classes (Moskowitz, Ooi and Pedersen, 2012; Baltas and Kosowski, 2013); its relation with volatility states (Petterson, 2014); and its optimal implementation by traders (Hurst, Ooi and Pedersen, 2013, 2014; Levine and Pedersen, 2016; Baltas and Kosowski, 2015). Comparatively little attention has been devoted, however, to the most conventional of asset classes: common stocks.

Our paper addresses this gap, investigating time-series momentum in equities markets. We document the strong presence of time-series momentum (henceforth TSMOM) in individual stocks. ${ }^{1}$ From 1927 to 2017, a TSMOM portfolio which takes long positions in positive past return stocks and short positions in negative past return stocks generated a statistically significant value-weighted monthly return of $0.76 \%$. The effect persists after accounting for standard risk factors (CAPM, Fama-French three-factor and Fama-French five-factor models), firm size, and macroeconomic factors. Moreover, TSMOM returns remain positive and significant for four subsample periods and for virtually all alternative formation- and holding-period combinations.

\footnotetext{
${ }^{1}$ Many studies document the robust profitability of a cross-sectional momentum strategy in the US stock markets (Jegadeesh and Titman, 1993, 2002; Grundy and Martin, 2001; As ness, Moskowitz and Pedersen, 2013; Novy-Marx, 2012). Cross-sectional momentum strategies have also been documented in international equity markets (Rouwenhorst, 1998; Liew and Vassalou, 2000; Griffin, Ji and Martin, 2003; Chui, Titman and Wei, 2010). The cross-sectional momentum effects are robust not only in individual stocks but also in other asset classes, including industry, equity index, currency, commodity and global bond futures (Shleifer and Summers, 1990; Asness, Liew and Stevens, 1997; Moskowitz and Grinblatt, 1999; Bhojraj and Swaminathan, 2006; Erb and Harvey, 2006; Gorton, Hayashi and Rouwenhorst, 2013; Asness, Moskowitz and Pedersen, 2013).
} 
We investigate whether the profitability of TSMOM varies depending on market conditions. Cujean and Hasler (2017) posit that disagreement, driven by heterogeneity in investors' learning speeds, should increase in bad states, such that time-series momentum is stronger in bad states than in good states. Classifying a month's market state by its ex-post market risk premium, we observe that TSMOM produces positive and significant returns during down markets, moderate returns during normal markets and negative and significant returns during up markets. Da, Gurun and Warachka (2014) document that the strength of a cross-sectional momentum strategy is higher for stocks whose information arrives continuously (as opposed to discretely). We find that this phenomenon characterizes timeseries momentum as well. Monthly TSMOM profits increase from $0.50 \%$ for stocks with discrete information to $1.15 \%$ for those with continuous information. Huang, Jiang, Tu and Zhou (2015) show that investor sentiment can predict aggregate stock market returns. High sentiment (optimism) precedes lower returns, consistent with optimism effecting overpricing. We document that both raw and risk-adjusted TSMOM returns increase with sentiment.

A consideration with TSMOM is the degree to which it overlaps with traditional crosssectional momentum (CSMOM). By construction, a TSMOM portfolio will overlap with its CSMOM counterpart, and what we document as TSMOM could simply be an artifact of that overlap. When we regress TSMOM returns on the Fama-French-Carhart four-factor model, which includes the cross-sectional momentum factor, we find that the TSMOM alpha is not statistically significant. While this result might suggest that TSMOM is subsumed by CSMOM, Goyal and Jegadeesh (2018) argue that in the context of stocks, a key difference between TSMOM and CSMOM involves their respective weighting schemes. CSMOM is dollar-neutral (zero net investment) while TSMOM is not. When we regress dollar-neutral TSMOM returns on the four-factor model, we observe a positive and significant alpha. The differential outcomes for dollar- and non-dollar-neutral strategies validate Goyal and 
Jegadeesh's claim regarding the importance of weighting schemes in comparing TSMOM and CSMOM.

TSMOM involves taking positions across all publicly traded assets, a strategy which investors may not prefer in the context of equities, which number in the thousands. To address this problem, we propose two alternative implementations: revised TSMOM, which takes positions only in stocks with a greater than one standard deviation absolute return, and dual momentum, which combines both TSMOM and CSMOM. Both strategies generate statistically significant profits while requiring investment in roughly one-fifth the number of stocks as TSMOM. Revised TSMOM generates raw returns of $1.55 \%$ per month and a FamaFrench three-factor alpha of $1.74 \%$. The dual-momentum strategy first sorts stocks into two groups by the signs of their prior returns, as in TSMOM; within each group, it then sorts stocks into quintiles, as in CSMOM. The strategy takes a long position in the highest quintile of the positive return group and a short position in the lowest quintile of the negative return group. A value-weighted dual-momentum strategy generates a striking monthly return of $1.71 \%$ over the sample period, higher than either TSMOM or CSMOM individually.

For robustness, we examine whether transaction costs, aggregate momentum, or geography can account for the profitability of TSMOM. Transaction costs have been demonstrated to eliminate CSMOM effects (Lesmond, Schill and Zhou, 2004; Korajczyk and Sadka, 2004), and we test whether they eliminate TSMOM effects as well. The results for TSMOM are mixed, depending on the measurement of returns and turnover, but generally remain robust for revised TSMOM and dual momentum. Neely, Rapach, Tu and Zhou (2014) document that the sign of the past $\mathrm{S} \& \mathrm{P} 500$ return predicts the risk premium in the future, effectively demonstrating TSMOM at the aggregate level. To determine whether our TSMOM returns are separate from aggregate momentum (AGMOM), we regress TSMOM on AGMOM and vice versa. The results suggest that time-series momentum drives aggregate 
momentum but not the reverse. As CSMOM has been found to exist not only in US markets but also in international markets (Rouwenhorst, 1998; Griffin, Ji and Martin, 2003; Asness, Moskowitz and Pedersen, 2013), we investigate whether TSMOM characterizes international markets as well. Raw TSMOM returns are positive and significant in all 13 markets that we test, and risk-adjusted returns are positive and significant in 12 of the 13 markets. In all cases, the estimated raw and risk-adjusted returns are of similar magnitudes as those observed for the US. The global results suggest that data mining is an unlikely explanation for our main (US-based) results.

The paper proceeds as follows. In Section 2 we describe the sample and document TSMOM in equities. In Section 3 we test whether TSMOM can be explained by exposure to standard risk factors, by firm size, or by macroeconomic factors. Section 4 investigates the relation between market conditions and TSMOM. In Section 5 we compare time-series momentum to cross-sectional momentum. In Section 6 we address implementation, transaction costs, robustness tests and international markets. Section 7 concludes.

\section{TSMOM in Equities}

\subsection{Sample Construction}

Each observation in our sample corresponds to a unique stock-month. The primary sample consists of all stocks listed on the NYSE, NASDAQ and AMEX available on CRSP from 1926 to 2017. To estimate risk-adjusted returns (alphas), we take the monthly risk-free rate, the Fama-French-Carhart four factors, and the Fama-French five factors from Kenneth French's website. ${ }^{2}$ In addition, we construct time series of several macroeconomic variables. The term spread (TERM) and the default spread (DEF) are obtained from the Federal Reserve

\footnotetext{
${ }^{2}$ http://mba.tuck.dartmouth.edu/pages/faculty/ken.french/data_library.html
} 
Bank's interest rate data. ${ }^{3}$ The dividend yield (DIV) is calculated as the total dividend payments accruing to the CRSP value-weighted index, divided by the current level of the index. The risk-free rate is the yield on three-month Treasury bills. The growth in the gross domestic product (GDP) is sourced from Datastream.

To test TSMOM in international markets, we obtain monthly stock data for Austria, Belgium, Denmark, France, Germany, Italy, the Netherlands, Norway, Spain, Sweden and Switzerland via Datastream. With two exceptions, the start year in each of the markets in the sample is 1975; Spain and Sweden have start years of 1988 and 1984, respectively. We additionally pull data for UK markets from the London Share Price Database, with the sample covering 1956 to 2017 . All prices and returns are expressed in the local currency.

\subsection{Portfolio Formation}

For each month $t$, we assign each stock to one of two groups, winner or loser, based on the sign of the prior-year returns, measured over months $t-12$ to $t-2 .{ }^{4}$ The resulting month $t$ winner portfolio consists of stocks with positive prior returns; the corresponding loser portfolio consists of stocks with negative prior returns. The TSMOM strategy takes long positions in the winners and short positions in the losers. The return on the combined winnerminus- loser (WML) portfolio over the subsequent month is our primary unit of observation.

Within the individual winner and loser portfolios we use three weighting schemes: value, volatility and equal. Each stock in the value-weighted winner portfolio is weighted by its market value, divided by the sum of the market values of all winner stocks. For volatility weights, we estimate volatility using daily returns over the formation period. Each stock in the volatility-weighted winner portfolio is weighted by its inverse volatility, divided by the

\footnotetext{
${ }^{3}$ Term spread (TERM) is measured by the difference between the average yield of Treasury bonds with more than ten years to maturity and the yield of one-month T-bills. Default spread (DEF) is measured by the difference between the average yield of bonds rated Baa by Moody's and the av erage yield of bonds rated Aaa. ${ }^{4}$ There is a one-month skip between the formation and holding periods (i.e., month $t-1$ ), in order to avoid microstructure bias (Jegadeesh, 1990; Lehmann, 1990).
} 
sum of the inverse volatilities of all winner stocks. Given $n$ stocks in the winner portfolio, each stock in the equal-weighted winner portfolio is weighted by $1 / n$. Loser portfolios are constructed in the same manner as winner portfolios.

\subsection{TSMOM Results}

Table 1 reports summary statistics for TSMOM monthly returns for each weighting scheme. In all cases, the WML portfolio is negatively skewed (e.g., monthly skewness of -1.48 for volatility weighting). The beta of the loser portfolio is higher than that of the winner portfolio; as a result, the beta of the WML portfolio is slightly negative. The time-series winners are relatively large firms (with an average market cap of $\$ 1,287$ million), while the time-series losers are relatively small firms (with an average market cap of \$569 million).

\section{[Insert Table 1 here]}

Most importantly, over the full sample period, all three schemes produce significant profits. The value-, volatility- and equal-weighted TSMOM strategies generate average monthly excess returns of $0.76 \%, 0.80 \%$ and $0.86 \%$, respectively, all of which are statistically significant at the $1 \%$ level. Though not adjusted for risk, the magnitude of these results provides preliminary evidence that TSMOM characterizes equity markets.

\section{Risk-Adjusted Returns}

This section considers whether TSMOM returns simply reflect exposure to risk factors or firm characteristics which the as set pricing literature has previously established. Specifically, we investigate the robustness of TSMOM to common risk factors, firm size and macroeconomic factors. 


\subsection{Pricing Models}

We test TSMOM returns using three standard asset pricing models: the Capital Asset Pricing Model (CAPM), the Fama-French (1996) three-factor model (FF3) and the Fama-French (2015) five-factor model (FF5). ${ }^{5}$ Specifically, we estimate the following equations:

$$
\begin{aligned}
& R_{W M L, t}=\alpha_{W M L}+\beta_{W M L}\left(R_{M K, t}-R_{f, t}\right)+\varepsilon_{W M L, t}, \\
& R_{W M L, t}=\alpha_{W M L}+\beta_{W M L}\left(R_{M K, t}-R_{f, t}\right)+s_{W M L} S M B_{t}+h_{H M L} H M L_{t}+\varepsilon_{W M L, t}, \\
& R_{W M L, t}=\alpha_{W M L}+\beta_{W M L}\left(R_{M K, t}-R_{f, t}\right)+s_{W M L} S M B_{t}+h_{H M L} H M L_{t}+r_{W M L} R M W_{t}+c_{W M L} C M A_{t}+\varepsilon_{W M L, t},
\end{aligned}
$$

$\mathrm{R}_{\mathrm{WML}, \mathrm{t}}$ is the return of the TSMOM strategy in month $t, \mathrm{R}_{\mathrm{MKT}, \mathrm{t}}$ is the return of the market portfolio and $\mathrm{R}_{\mathrm{f}, \mathrm{t}}$ is the risk-free return. $\mathrm{SMB}_{\mathrm{t}}$ is the difference between the returns on diversified portfolios of small and large stocks. $\mathrm{HML}_{\mathrm{t}}$ is the difference between the returns on diversified portfolios of high- and low book-to-market stocks. RMW $\mathrm{W}_{\mathrm{t}}$ is the difference between the returns on diversified portfolios with robust and weak profitability. $\mathrm{CMA}_{t}$ is the difference between the returns on diversified portfolios of low- and high-investment firms.

Regression results are reported in Table 2. Panels A, B and C respectively correspond to value, volatility and equal weights. Each panel has three columns, one for each model (CAPM, FF3, FF5). Across the three panels we observe several consistent trends. First and foremost, the intercept term - i.e., the alpha - is positive and significant regardless of the model used, suggesting that exposure to these factors does not, by itself, explain TSMOM. Second, the adjusted $\mathrm{R}^{2} \mathrm{~s}$ are low, suggesting that variation in the factor returns is not driving the variation in TSMOM returns. Overall, the evidence in Table 2 suggests that the TSMOM effects are not subsumed by the inclusion of standard risk factors.

[Insert Table 2 here]

\footnotetext{
${ }^{5}$ Pricing tests using the Fama-French-Carhart four-factors are discussed in Section 5, in which we analyze the potential overlap between TSMOM and CSMOM.
} 


\subsection{Firm Size}

Earlier, in Table 1, we documented an asymmetry in the market caps of winners versus losers. Winners tend to be larger than losers, a fact which raises the possibility that the TSMOM effects are driven by firm size. Smaller stocks are on average less liquid, covered less by analysts, and more expensive to trade (e.g., Keim and Stambaugh, 1986; Brennan, Chordia and Subrahmanyam, 1998; Novy-Marx and Velikov, 2016), characteristics which may attenuate the economic importance of the earlier results.

To address this, each month we split stocks into small-, medium- and large-cap groups based on their market capitalizations relative to the $30^{\text {th }}$ - and $70^{\text {th }}$-percentile NYSE size breakpoints. Within each size group we construct the TSMOM winner-minus- loser portfolios and then rerun our earlier tests.

In Table 3 we report raw returns as well as alphas estimated from the CAPM, FF3 and FF5 models for each size group. Panels A, B and C respectively report results using value, volatility and equal weights to construct the WML portfolios. In nearly all pricing model/weighting scheme/firm size permutations, the (risk-adjusted) WML returns are positive and significant. TSMOM is not limited to small caps and remains profitable even when constrained to large, liquid stocks. Moreover, it is not necessarily the case that the profitability of the WML portfolio decreases with firm size. Only with equal-weighted WML portfolios do we observe insignificant alphas, and these cases are restricted to small, as opposed to large, firms. In short, the effectiveness of TSMOM does not require trades in small, potentially illiquid stocks.

[Insert Table 3 here] 


\subsection{Macroeconomic Factors}

Insofar as TSMOM is related to market conditions, it is natural to question whether its effects are driven by exposure to macroeconomic risk. ${ }^{6}$ We test whether the TSMOM is robust to adjustments for macroeconomic risks. Specifically, we run the following regression ${ }^{7}$ :

$$
R_{W M L, t}=\alpha_{W M L}+\beta_{1} D I V_{t-1}+\beta_{2} Y L D_{t-1}+\beta_{3} T E R M_{t-1}+\beta_{4} D E F_{t-1}+\beta_{5} G D P_{t-1}+\varepsilon_{W M L, t},
$$

where $\mathrm{R}_{\mathrm{WML}}$ is the excess returns of the momentum strategies at month $t$, DIV is the onemonth lagged dividend yield on the market, YLD is the one-month lagged yield of a threemonth T-bill, TERM is the one-month lagged term spread (measured as the difference between the average yield of Treasury bonds with more than ten years to maturity and the yield of one-month T-bills), DEF is the one-month lagged default spread (measured by the difference between the average yield of bonds rated Baa by Moody's and the average yield of bonds rated Aaa), and GDP is the one-month lagged GDP growth. The sample period is from 1951 to 2017 , to match the data availability of the macroeconomic risk variables.

Estimated coefficients are presented in Table 4. For value- and volatility-weighted WML portfolios, the intercept is positive and significant, while for equal-weighted WML portfolios, the intercept is positive but not significant at the $10 \%$ level. The results suggest that TSMOM is not driven purely by exposure to the included macroeconomic factors, with only the DEF coefficient being significant across all three weighting schemes. Overall, the findings suggest that TSMOM is at best weakly related to macroeconomic risk.

[Insert Table 4 here]

\footnotetext{
${ }^{6}$ There are longstanding debates whether macroeconomic risk can account for the sources of cross -sectional momentum profits. Chordia and Shivakumar (2002) and Liu and Zhang (2008) claim that macroeconomic risk can explain momentum profits, while Griffin, Ji and Martin (2003) contend the opposite.

${ }^{7}$ The regression model follows Chordia and Shivaku mar (2002) and Griffin, Ji and Martin (2003), aug mented with an additional macroeconomic factor: GDP growth (Asness, Moskowitz and Pedersen, 2013).
} 


\section{TSMOM and Market Conditions}

We next consider whether the profitability of TSMOM varies depending on market conditions. Specifically, we investigate TSMOM returns conditional on the market state, on the information discreteness of individual stocks, and on investor sentiment.

\subsection{Market State}

Daniel and Moskowitz (2016) document that crashes in the profitability of CSMOM tend to follow market declines, as the market rebounds. As TSMOM splits the market portfolio into two groups and takes long-short positions in them, insofar as TSMOM captures autocorrelation and that autocorrelation is state-dependent, there should be a relation between the market state and the contemporaneous TSMOM return. ${ }^{8}$

We employ contemporaneous market returns to estimate the state-dependent performance of the TSMOM strategies, similar to Daniel and Moskowitz (2016). ${ }^{9}$ Using both the S\&P 500 index and the CRSP value-weighted market index as proxies for the market, we sort monthly market returns into deciles based on their ranks over the full sample period. A rank of 1 corresponds to months in which the market return was in the lowest $10 \%$ of all monthly market returns (i.e., extremely bad times); a rank of 10 is given to months in which the market return was in the top $10 \%$ (i.e., extremely good times). In Table 5 we tabulate average monthly WML returns against the contemporaneous market return rank. Panel A uses the S\&P 500 as the market return; Panel B uses the CRSP value-weighted index.

\footnotetext{
${ }^{8}$ We thank the referee for the suggestion of investigating the performance of time-series momentum across different market conditions and across different states of investor sentiment.

${ }^{9}$ In unreported results, we also conducted the analysis using alternative definitions of the market states based on prior-period SP index returns and find largely consistent results. For example, we alternatively define extre mely good (extremely bad) times when the returns of the S\&P 500 index increase (decrease) by $25 \%$ in the prior year. If the S\&P 500 prior-year returns are greater than $25 \%$, then the average return to TSMOM is $0.59 \%$ in the following month; if the S\&P prior-year return suffered statistically significant losses (less than $-25 \%$ ), then the average return of TSMOM strategy is $1.00 \%$.
} 
[Insert Table 5 here]

Both panels show the same approximate pattern, regardless of the weighting scheme used. TSMOM effects are strongest during extreme bear markets (rank 1); moderate in moderate markets (ranks 2 through 7, inclusive); and deteriorate in the best market conditions, crashing in extreme bull markets (rank 10). These results echo the estimates of the (market) beta of the WML portfolio returns in Tables 1 and 3, which are negative in most specifications.

The countercyclical nature of TSMOM is consistent with Cujean and Hasler (2017). In their model, investors assess information differently from one another and accordingly update their beliefs at different speeds conditional on the state of the economy. In good states, investors revise their beliefs at comparable speeds and have little disagreement. In bad states, however, differences in investors' learning speeds widen, manifesting in higher disagreement among investors. Under- and over-reaction by different sets of investors generate time-series momentum; since disagreement tends to spike during bad states, time-series momentum should be stronger in bad states.

\subsection{Information Discreteness}

Da, Gurun and Warachka (2014) investigate whether investor inattention explains crosssectional momentum profits. Their "frog-in-the-pan" (FIP) hypothesis states that investors pay less attention to information that arrives continuously in small amounts than information that arrives discretely in large amounts. Consistent with this hypothesis, they document that CSMOM profits are higher for continuous-information stocks than for discrete-information stocks.

If TSMOM is driven by investor inattention to continuously-arriving information, there should be a monotonic increase in momentum profits as the granularity of information increases. As with CSMOM, the FIP hypothesis implies that the effects of TSMOM should 
be stronger for stocks with continuously arriving information than for those with discretely arriving information.

Following Da, Gurun and Warachka (2014), we define a proxy variable, information discreteness (ID), for each stock-month to measure the extent to which information is discrete or continuous:

$$
I D=\operatorname{sign}(\mathrm{PRET}) \times[\% \text { neg }-\% \text { pos }],
$$

where PRET is the cumulative return during the formation period, sign(PRET) is the sign (positive or negative) of PRET and \% neg and \%pos represent the percentages of days during the formation period with negative and positive returns, respectively. A large ID represents discrete information, while a small ID represents continuous information.

We form both sequential double-sorted portfolios and independent double-sorted portfolios by the prior 11-month return (winner or loser) and the discreteness proxy (ID). For the sequential double-sort, we first sort the stocks into the two TSMOM groups by the sign of the formation period returns and then, within each momentum group, further sort the stocks into quintiles by ID in descending order, such that the highest quintile (5) corresponds to the most continuously arriving information. For the independent double-sort, we first sort stocks into TSMOM groups and then independently sort them into quintiles according to the descending ID ranking.

In Panel A of Table 6 we report the monthly average raw and risk-adjusted returns for the sequential double-sorted portfolios. The results largely confirm the FIP hypothesis. Whether measured with raw returns or alphas, the WML returns increase monotonically with the granularity of information arrival. Panel B lists the returns to the independent doublesorted portfolios. The average raw returns decrease through the first four ID quintiles before increasing over the highest ID quintile. By comparison, CAPM, FF3 and FF5 alphas all increase monotonically with the ID quintiles. Overall, tests for both the sequential and 
independent double-sorted portfolios are largely consistent with theories on limited attention and investor underreaction (e.g., Hou, Peng and Xiong, 2009; Da, Gurun, and Warachka, 2014; Byun, Lim and Yun, 2016), wherein investors tend to underreact more often to information that arrives continuously in small amounts than to information that arrives discretely in large amounts.

[Insert Table 6 here]

\subsection{Investor Sentiment}

Huang, Jiang, Tu and Zhou (2015) document that investor sentiment predicts aggregate stock market returns. When sentiment is high-i.e., when investors are optimisticcontemporaneous prices are high, which implies low future returns. Given this dynamic, we test whether TSMOM effects are conditional on sentiment.

We estimate sentiment using the aligned investor sentiment index of Huang et al. (2015). ${ }^{10}$ This index is a refinement of the sentiment index developed by Baker and Wurgler (2006), using the same six individual measures: the close-end fund discount rate, share turnover, number of IPOs, average first-day returns of IPOs, dividend premium and equity share in new issues. ${ }^{11}$ Using the aligned investor sentiment index limits our sample to September 1965 to December 2014.

To classify the formation period ending prior to month $t$, we follow Antoniou, Doukas and Subrahmanyam (2013) and take a weighted rolling average of the sentiment index over

\footnotetext{
${ }^{10}$ The index is available from Dashan Huang's website.

${ }^{11}$ In unreported results, we run similar tests using Baker and Wurgler's (2006) and more recent five-indicator sentiment indices and observe different results. Rather than positive and significant TSMOM returns occurring in optimistic states, as under the Huang et al. (2015) definition, high TSMOM returns occur in mild states under either of the Baker and Wurgler definitions. By design, Huang et al.'s sentiment index generates different sentiment scores from Baker and Wurgler's (2006) index and, by extension, their updated index. The aligned sentiment index's correlation is 0.73 with the former and 0.58 with the latter. We interpret the different TSMOM results across the indices as an artifact of the differences in the indices' respective classifications of a given month's sentiment. Our reported results assume that Huang et al.'s (2015) claim to offer an improved measure of sentiment over that of Baker and Wurgler (2006) is correct.
} 
the previous three months. Sentiment is given a weight of 3 in month $t-1,2$ in month $t-2$ and 1 in the month $t-3$. We first categorize the top $30 \%$ of formation-period weighted rolling averages as optimistic states and the bottom $30 \%$ as pessimistic. In unreported results, we also consider cut-offs at $40 \%$; the results are similar.

In Table 7 we report monthly raw returns and CAPM, FF3 and FF5 alphas conditional on the formation period sentiment state. Both raw and risk-adjusted TSMOM returns increase with the sentiment state. Raw value-weighted TSMOM returns are $0.99 \%(t=2.02)$ when the aggregate investor sentiment is optimistic and $0.08 \%(t=0.22)$ when it is pessimistic. FF5 alphas are $1.16 \%(t=2.15)$ when sentiment is optimistic and $0.21 \%(t=0.42)$ when it is pessimistic. Overall, high investor sentiment is associated with higher subsequent TSMOM profits. Insofar as down markets tend to follow optimistic states, the results here are consistent with those in Table 5, which show TSMOM being most profitable in down markets.

[Insert Table 7 here]

\section{Comparison to Cross-Sectional Momentum}

We investigate the extent to which TSMOM is distinct from CSMOM. Moskowitz, Ooi and Pedersen (2012) provide decompositions of CSMOM and TSMOM and demonstrate that returns to the two strategies are driven in part by a common component: the autocovariance in asset returns. Conceptually, a TSMOM portfolio should overlap with the corresponding CSMOM portfolio in terms of the sign, though not the weight, of the position in a given asset. In a market with ten securities, a CSMOM strategy that ranks the securities by their prior returns will go long the best-performing stock and short the worst-performing stock. A TSMOM strategy will go long the securities with positive prior returns and short the securities with negative prior returns. If at least one stock has a negative prior return and at 
least one stock has a positive prior return, the CSMOM positions will be subsets of the TSMOM positions. The differences in the strategies lie in the composition of the middle stocks contained in TSMOM but not in CSMOM, and in the respective weighting schemes of the TSMOM and CSMOM portfolios.

Goyal and Jegadeesh (2017) observe that CSMOM and TSMOM are not directly comparable, since the former is dollar-neutral while the latter is not. Their approach is to combine the CSMOM portfolio with a time-varying investment in the market portfolio such that the combined position has the same net investment as the corresponding TSMOM portfolio.

Our approach is to compare both non-dollar-neutral and dollar-neutral TSMOM strategies to CSMOM. For each weighting scheme, we generate two sets of TSMOM portfolios: non-dollar-neutral and dollar-neutral. Non-dollar-neutral portfolios are those described in Section 2 and used throughout this paper. Dollar-neutral portfolios are similar in construction except that the winner and loser portfolios are scaled to have the same dollar value, such that the combined WML portfolio is zero-investment.

We run standard asset pricing tests for TSMOM returns inclusive of the Carhart (1997) momentum factor (UMD) to determine whether TSMOM is indeed distinct from CSMOM. Table 8 reports estimated coefficients from regressing TSMOM returns on the Fama-FrenchCarhart (FFC) four factors. Panels A, B and C correspond to value-, volatility- and equalweights, while the two columns within each panel correspond to non-/dollar-neutral portfolios.

\section{[Insert Table 8 here]}

Two basic patterns are observed. First, the coefficient on UMD is positive and significant in every case, suggesting that a common component drives both TSMOM and CSMOM. Second, alphas are not statistically significant for non-dollar-neutral portfolios but 
are positive and significant for dollar-neutral portfolios. This differential result across dollarneutral and non-dollar-neutral portfolios injects some uncertainty into the distinction between TSMOM and CSMOM. On the one hand, non-dollar-neutral TSMOM (which is to say, consistent with Moskowitz, Ooi and Pedersen (2012)) appears to be subsumed by CSMOM. On the other hand, dollar-neutral TSMOM (which is more directly comparable to CSMOM) has a component distinct from CSMOM. What our analysis does confirm is the observation made in Goyal and Jegadeesh (2017) that the net investment is a factor in distinguishing TSMOM and CSMOM.

\section{Implementation and Robustness}

\subsection{Implementation}

Applied to equity markets, a TSMOM strategy involves a position in every listed stock. In our sample, this corresponds to investments in an average of 2,645 stocks each month $(1,464$ winners and 1,181 losers, according to Table 1). Such a broad investment strategy may be impractical for an investor to implement. Accordingly, we propose two refinements to TSMOM which reduce the number of assets in which to invest: revised time-series momentum, which limits investment to stocks with more extreme price movements and dual momentum, which combines time-series and cross-sectional momentum into a single strategy.

\subsubsection{Revised TSMOM}

Our revised TSMOM (RTSMOM) strategy limits investment only to stocks whose absolute prior-year returns are greater than one standard deviation. ${ }^{12}$ For a given stock in month $t$, we

\footnotetext{
${ }^{12}$ We thank Bruce Grundy for suggesting this idea.
} 
calculate both its absolute prior-year return over month $t-12$ to $t-2$ and its standard deviation over months $t-23$ to $t-13$.

In Panel A of Table 9 we present summary statistics for the value-weighted winner, loser and winner-minus-loser RTSMOM portfolios. Compared to the corresponding results in Panel A of Table 1, the winner portfolio returns are higher and the loser portfolio returns are lower for RTSMOM, while the number of stocks shrinks by more than one-half for the winner portfolio and by more than three-quarters for the loser portfolio. Panel B lists coefficient estimates from the CAPM, FF3 and FF5 pricing models. Again, compared to corresponding TSMOM results in Table 2, the returns for RTSMOM are on average higher than for TSMOM. Panel C reports results from the difference test between RTSMOM and TSMOM. We find that RTSMOM is statistically different from TSMOM. In sum, compared to standard TSMOM, the revised TSMOM strategy both requires fewer positions and generates higher returns.

[Insert Table 9 here]

\subsubsection{Dual-Momentum}

We next propose a dual-momentum strategy that combines elements of both TSMOM and CSMOM. The strategy involves sequential double sorts, first by the sign of the formation period return and then by the rank. Specifically, we assign stocks to a time-series loser (T1) group if the prior 11-month returns are negative and to a time-series winner (T2) group if these returns are positive. Within the two TSMOM groups, the stocks are further ranked into quintiles based on the prior 11-month returns, where P1 is the value-weighted portfolio of stocks in the worst-performing $20 \%$ and P5 is the value-weighted portfolio of stocks in the best-performing $20 \%$. The dual momentum strategy buys the strongest winner portfolio (T2P5) and short sells the weakest loser portfolio (T1P1) with zero net investment. 
Panel A of Table 10 presents summary statistics for the dual momentum portfolios. The value-weighted monthly return of the dual momentum strategy is $1.74 \%$, which is more than double that of the TSMOM strategy $(0.76 \%$ in Table 1$) .{ }^{13}$ The dual momentum winnerminus- loser returns are driven almost entirely by the winner (T2P5) portfolio, with the loser (T1P1) portfolio generating a near-zero return. The high WML returns come with higher risk, however: the associated volatility is $14.96 \%$ per month. As expected, the number of stocks in the dual momentum portfolios drops by roughly four-fifths relative to their TSMOM counterparts.

\section{[Insert Table 10 here]}

In Panel B we test whether the returns of the dual momentum strategy are due to their exposure to common factors. Columns 1, 2 and 3 correspond to CAPM, FF3 and FF5 pricing models. In all cases, we observe that the alpha remains positive and significant.

Finally, in PanelC we report results from difference tests between dual momentum and TSMOM as well as between dual momentum and CSMOM. In both cases, we find that dual momentum is statistically different from either TSMOM or CSMOM.

\subsection{Transaction Costs}

Similar to many previous studies, this paper focuses on gross returns, which are the most suitable for understanding the relation between risk and returns. In practice, however, gross returns overstate the profits earned by the strategies examined. We next analyze the implications of transaction costs.

\footnotetext{
${ }^{13}$ Korajczyk and Sadka (2004) suggest that after price impacts are taken into account, value-weighted momentum strategies perform better than equal-weighted momentum strategies. They find that a break-even point is $\$ 200$ million that may be invested in an equal-weighted CSMOM strategy, using an 11 -month portfolio formation and three-month portfolio holding with a one-month skip in between, before the apparent profit opportunities vanish, while the break-even point is $\$ 2$ billion for the corresponding value-weighted strategy. Thus, we focus our analysis on the value-weighted portfolios.
} 
Lesmond, Schill and Zhou (2004) and Korajczyk and Sadka (2004) examine transaction costs and the market impact of CSMOM strategies in light of their high turnover. The studies show that net returns of CSMOM strategies are considerably lower than their gross returns. ${ }^{14}$ More recently, however, Frazzini, Israel and Moskowitz (2015) demonstrate that the trading costs of CSMOM are lower for large institutions than those implied by the calibrated models of these earlier two papers. The authors show that the break-even fund size on the CSMOM strategy could be about $\$ 5.2$ billion among US securities. As a result, they conclude that the strategies can still generate strong net returns.

To estimate transaction costs associated with turnover in TSMOM portfolios, we follow Novy-Marx and Velikov (2016), who write: "Transaction costs consequently reduce realized value-weighted spreads by more than $1 \%$ of the monthly one-sided turnover." Accordingly, we estimate transaction costs by using monthly turnover ratios multiplied by one percent.

To calculate turnover ratios, we use two methods:

1. $\operatorname{Min}(S E C)$ conforms to the SEC definition and is computed as the lesser of purchases or sales, divided by the average of portfolio assets.

2. Max is computed as the maximum of purchases or sales, divided by the average of portfolio assets.

Table 11 reports value-weighted TSMOM turnover, gross raw returns, net raw returns and alphas inclusive of estimated transaction costs. In Panel A, turnover and returns correspond to a value-weighted TSMOM strategy. The different turnover ratio methods generate different net returns and therefore different alphas. Net returns are positive for both methods but significant only using the $\operatorname{Min}(S E C)$ calculation. Regardless of the turnover ratio

\footnotetext{
${ }^{14}$ Korajc zyk and Sadka (2004) show that the profit of the equal-weighted cross-sectional mo mentum strategy could be largely reduced by transaction costs. They find that after accounting for trading costs, the value weighted momentum strategy performs better than the equal-weighted strategy.
} 
calculation, CAPM and FF3 alphas are positive and significant and FF5 alphas are insignificant.

\section{[Insert Table 11 here]}

In Panel B we report results for the revised TSMOM (RTSMOM) strategy. Given the higher returns of RTSMOM relative to TSMOM, we should expect it to be more robust to transaction costs. The results largely confirm this: net returns, CAPM alphas and FF3 alphas are positive and significant regardless of the turnover ratio calculation. The FF5 alpha is positive and significant for the $\operatorname{Min}(S E C)$ ratio, but insignificant otherwise.

Finally, in Panel C we report results for the dual momentum strategy. In this case, we observe that net returns and alphas for all three pricing models are positive and significant for both the Min(SEC) and Max turnover ratios.

Overall, the results suggest that while transaction costs diminish the returns for TSMOM, RTSMOM and dual momentum, they do not necessarily eliminate them.

\subsection{Short Sales}

A time-series momentum strategy involves taking short positions in stocks, and shorting incurs costs. If our results were driven by the short side and if shorting were sufficiently costly, the real-world efficacy of the strategy would be undermined. A direct test is not feasible since our sample runs 91 years, well beyond the availability of reliable short-sale costs (e.g., from Markit).

This deficiency may not, however, be relevant. The TSMOM strategy is diminished by shorting the loser portfolio. In our tests with the separate winner and loser portfolios (e.g., Tables 2 and 4), the loser portfolio on average has a positive return associated with it, such that the resulting winner-minus- loser portfolio has a lower return than the winner portfolio alone. Excess returns $\left(\overline{\mathrm{r}-\mathrm{r}_{\mathrm{f}}}\right)$ on the winner portfolio imply that borrowing at the risk-free 
rate to finance a long position in the winner portfolio should on average generate higher returns than the TSMOM WML portfolio. That is, TSMOM is more profitable without taking short positions in the losers. Even if shorting is prohibitively expensive for the loser portfolio, our results suggest that a leveraged long TSMOM winner portfolio will be profitable.

\subsection{Aggregate Momentum}

Neely, Rapach, Tu and Zhou (2014) document that technical indicators can match or outperform macroeconomic variables in predicting the equity risk premium, measured using the S\&P 500 to proxy for the market. In a simple bivariate regression, they demonstrate that the premium loads positively and significantly on the sign of the past S\&P 500 return. They effectively document TSMOM at the aggregate level: the sign of the past S\&P 500 return predicts the risk premium in the future.

To the extent that the S\&P 500 is a reasonable proxy for the market, aggregate momentum is a blunter version of the TSMOM strategy we document in this paper. An aggregate momentum (henceforth AGMOM) strategy takes a long (short) position in all stocks if the value-weighted average return of all stocks is positive (negative). If stock-level TSMOM is distinct from AGMOM, the TSMOM returns should outperform the corresponding AGMOM returns.

We test this by regressing TSMOM on AGMOM, and vice versa. Panels A, B and C of Table 12 report results for value-, volatility- and equal-weighted TSMOM portfolio returns. In all six regressions, the coefficient on the independent variable (TSMOM or AGMOM) is positive and significant, suggesting, as expected, that the two strategies are connected. However, the intercepts when regressing AGMOM on TSMOM are close to zero and not statistically significant, while the intercepts from regressing TSMOM on AGMOM are positive for all three weighting schemes and significant for two of the three. The results 
cumulatively align with our intuition that if TSMOM is distinct from AGMOM, it should outperform AGMOM.

\section{[Insert Table 12 here]}

\subsection{Alternative Formation and Holding Periods}

We constructed our TSMOM strategy by sorting stocks based on a 12-month formation period (prior 11-month returns plus one month skipped) and holding the WML portfolio for a one-month period. To test whether TSMOM is robust to alternative formation and holding periods, we construct WML portfolios based on $J$ month formation periods and $K$ month holding periods, where $J$ and $K$ equal 3, 6, 9 and 12, yielding 16 distinct $J / K$ combinations. Each month $t$, all stocks are assigned to winner and loser groups based on the signs of their cumulative returns from $t-2$ to $t-J-1$; the resulting WML portfolios are then held for $K$ months.

Panels A, B and C of Table A1 in the online appendix report the respective results for value-, volatility- and equal-weighted TSMOM portfolios across the different $J / K$ combinations. The results are broadly consistent across the three panels, in that for nearly every formation and holding period combination, the resulting WML return is positive and statistically significant. The few exceptions are concentrated at the two extreme corners: $J$ and $K$ equal to 3, and $J$ and $K$ equal to 12 . The sum of the evidence indicates that TSMOM effects are robust across different formations and holding periods.

\subsection{Sub-period Analyses}

The baseline results in Table 1, calculated using a 91-year window, do not tell us whether TSMOM was observed continuously over the sample period. Panel A of Table A2 in the online appendix reports the returns of TSMOM strategies in four subsample periods. The 
TSMOM strategy remains robust for three out four sub-periods, regardless of the weighting scheme. Using value weights, for example, the average monthly returns are $1.02 \%(t=1.40)$ in $1927-1949,0.88 \%(t=3.13)$ in $1950-1972,0.58 \%(t=1.76)$ in $1973-1995$ and $0.55 \%(t=$ 1.76) in $1996-2017 .^{15}$

In the CSMOM literature, January is a well-documented outlier, in that it generally produces losses (Jegadeesh and Titman, 1993; Grundy and Martin, 2001; Yao, 2012). ${ }^{16}$ We examine whether the same dynamic holds for TSMOM. We split each 23-year subsample into two subsamples-January-only and all other months - and report the resulting TSMOM subsample returns in Panel B of Table A2. In contrast to CSMOM, the TSMOM strategy exhibits negative but insignificant January losses regardless of the weighting scheme. The results for the remaining 11 months largely match the overall subsample averages.

\subsection{International Evidence}

We test whether the TSMOM effect we observe in US equities is also present in other international markets. Our motivation is rooted in the CSMOM literature, which has demonstrated the existence of CSMOM among common stocks in many other markets (Rouwenhorst, 1998; Griffin, Ji and Martin, 2003; Asness, Moskowitz and Pedersen, 2013).

We construct the TSMOM portfolios in 13 markets: Austria, Belgium, Canada, Denmark, France, Germany, Italy, the Netherlands, Norway, Spain, Sweden, Switzerland and the United Kingdom. Raw, CAPM-adjusted and FF3-adjusted returns are reported in Panel A

\footnotetext{
${ }^{15}$ In untabulated results we find that the worst monthly returns (i.e., the largest drawdowns) to the TSMOM strategies in the entire sample period of 1927-2017 are -28.49\% (August 1932), -20.14\% (January 1946) and $-20.03 \%$ (September 1939). The three worst monthly returns to the TSMOM strategies in the most recent subsample period of 1993-2017 are -17.76\% (January 2001), -11.41\% (April 2009) and -10.85\% (May 2000), which are smaller than those in the entire sample period. Despite some considerably negative returns in the earliest subsample periods to the TSMOM strategies, the average profits remain positive.

${ }^{16}$ According to Grundy and Martin (2001), the January losses of the cross -sectional mo mentum strategies are due to bets against the size effect in January. The prior winners tend to be small firms, while the prior losers tend to be extremely small firms. Buying s mall firms and selling extremely s mall firms results in betting against the size effect, which is strongest in January. Consequently, it results in the substantial losses for the crosssectional momentum strategies in January.
} 
of Table 13. In all 13 markets, raw WML returns are positive and significant. Similarly, CAPM and FF3 alphas are positive and significant in all but one market. We then pool all stocks first by continent and then into a single global market. In Panel B we report results for these joint tests based on TSMOM, revised TSMOM, and dual momentum strategies. For standard TSMOM, raw WML returns remain positive for Europe, North America and the combined market. However, of the 1990 to 2017 subsample returns ${ }^{17}$, CAPM alpha and FF3 alpha, only the CAPM and FF3 alpha for North America is positive and significant. For revised TSMOM, the estimated WML returns are positive and significant for every sample and every risk adjustment. For dual momentum, the returns are generally significant and more positive than the corresponding estimates for revised TSMOM, with the caveat that the statistical significance drops for Europe and North America in the 1990 to 2017 sample. Overall, the international results suggest that the TSMOM effects documented in this paper are not specific to the US market. The TSMOM strategy is primarily effective when limited to investment in a single country, although revised TSMOM is robust, and dual momentum may be robust, to investment across countries.

\section{[Insert Table 13 here]}

\section{Conclusion}

This study documents strong evidence of time-series momentum (TSMOM) in equities. The results indicate that time-series stock momentum has been a persistent phenomenon in the US equity markets over a 91-year period starting in 1927 and ending in 2017 . The effect of the strategy is robust to varying formation and holding periods, firm size groups and weighting schemes. Moreover, the effects of the strategy persist not only through time but also across

\footnotetext{
${ }^{17}$ We present the results in the sample period of July 1990 to September 2017, in addition to the whole sample period, to compare with the FF3 alphas, which are estimated using the European, North A merican and global version of those factors available from July 1990 only.
} 
international markets. Additionally, TSMOM alphas are positive and significant using CAPM, Fama-French three-factor and Fama-French five-factor models.

We test the effect of TSMOM conditional on the market state, information discreteness and market sentiment. TSMOM varies across market states, being strongest during (extreme) down markets and crashing during up markets. Following Da, Gurun and Warachka (2014), we observe that TSMOM returns are highest for stocks with continuously (as opposed to discretely) arriving information. This suggests that investor underreaction potentially drives TSMOM. With respect to market sentiment, TSMOM returns are highest when prior (formation-period) sentiment is high.

Our tests comparing TSMOM and CSMOM produce mixed results. Alphas for nondollar-neutral TSMOM, as originally described by Moskowitz, Ooi and Pedersen (2012) and used for the majority of our paper, are not statistically significant in estimates of the FamaFrench-Carhart four-factor model, which includes the CSMOM factor. However, alphas for dollar-neutral TSMOM, a strategy which is more directly comparable to CSMOM, are positive and statistically significant. We take these mixed results as support for the claim made in Goyal and Jegadeesh (2017) that the respective weighting schemes of TSMOM and CSMOM imply that the two strategies are not directly comparable.

To address the practical implementation of TSMOM, we propose two alternatives: revised TSMOM and dual momentum, both of which reduce the number of positions and increase the profitability relative to standard TSMOM. Including estimated transaction costs diminishes but does not necessarily eliminate the effects of revised TSMOM and dual momentum. 


\section{References}

Antoniou, C., Doukas, J. and Subrahmanyam, A., 2013. Cognitive dissonance, sentiment, and momentum. Journal of Financial and Quantitative Analysis, 48(1), 245-275.

Asness, C.S., Liew, J.M. and Stevens, R.L., 1997. Parallels between the Cross-Sectional Predictability of Stock and Country Returns. Journal of Portfolio Management, 23, 79-87.

Asness, C.S., Moskowitz, T.J. and Pedersen, L.H., 2013. Value and Momentum everywhere. Journal of Finance, 68(3), 929-985.

Baltas, A.N. and Kosowski, R., 2013. Momentum Strategies in Futures Markets and Trend following Funds. Working Paper, Imperial College.

Baltas, A.N. and Kosowski, R., 2015. Demystifying Time-Series Momentum Strategies: Volatility Estimators, Trading Rules and Pairwise Correlations. Working Paper.

Baker, M. and Wurgler, J., 2006. Investor sentiment and the cross-section of stock returns. Journal of Finance, 61, 1645-1680.

Bhojraj, S. and Swaminathan, B., 2006. Macromomentum: returns predictability in international equity indices. Journal of Business, 79, 429-451.

Brennan, M.J., Chordia, T. and Subrahmanyam, A., 1998. Alternative factor specifications, security characteristics, and the cross-section of expected stock returns. Journal of Financial Economics, 49(3), 345-373.

Byun, S.J., Lim, S.S. and Yun, S.H., 2016. Continuing overreaction and stock return predictability. Journal of Financial and Quantitative Analysis, 51(6), 2015-2046.

Chordia, T. and Shivakumar, L., 2002. Momentum, Business Cycle, and Time-varying Expected Returns. Journal of Finance, 57(2), 985-1019.

Chui, C.W., Titman, S., and Wei, K.C., 2010. Individualism and Momentum around the World. Journal of Finance, 65(1), 361-392.

Cujean, J. and Hasler, M., 2017. Why does return predictability concentrate in bad times? Journal of Finance, 72(6), 2717-2758.

Da, Z., Gurun, U.G. and Warachka, M., 2014. Frog in the Pan: Continuous Information and Momentum. Review of Financial Studies, 27(7), 2171-2218.

Daniel, K., Moskowitz, T.J., 2016. Momentum crashes. Journal of Financial Economics, 122(2), 221-247.

Erb, C. and Harvey, C., 2006. The tactical and strategic value of commodity futures. Financial Analyst Journal, 62, 69-97. 
Fama, E.F. and French, K.R., 1993. The Cross-Section of Expected Stocks Returns. Journal of Finance, 47(2), 427-465.

Fama, E.F. and French, K.R., 2015. A five-factor asset pricing model. Journal of Financial Economics, 116, 1-22.

Frazzini, A., Israel, R. and Moskowitz, T.J., 2015. Trading costs of asset pricing anomalies. Working Paper, Yale University.

Gorton, G.B., Hayashi, F. and Rouwenhorst, K.G., 20138. The Fundamentals of Commodities Futures Returns. Review of Finance, 17(1), 35-105.

Goyal, A. and Jegadeesh, N. 2018. Cross-Sectional and Time-Series Tests of Return Predictability: What Is the Difference? The Review of Financial Studies, 31(5), 1784-1824.

Griffin, J., Ji, X. and Martin, S.J., 2003. Momentum Investing and Business Cycle Risk: Evidence from Pole to Pole. Journal of Finance, 58(6), 2515-2547.

Grundy, B.D. and Martin, S.J., 2001. Understanding the Nature of the Risks and the Source of the Rewards to Momentum Investing, The Review of Financial Studies, 14(1), 29-78.

Hou, K., Peng, L. and Xiong, W., 2009. A Tale of Two Anomalies: The Implications of Investor Attention for Price and Earnings Momentum. Working Paper, Princeton University. Huang, D., Jiang, F., Tu, J. and Zhou, G., 2015. Investor sentiment aligned: A powerful predictor of stock returns. Review of Financial Studies, 28(3), 791-837.

Hurst, B., Ooi, Y.H. and Pedersen, L.H., 2013. Demystifying Managed Futures. Journal of Investment Management, 11(3), 42-58.

Hurst, B., Ooi, Y.H. and Pedersen, L.H., 2014. A Century of Evidence on Trend-Following Investing. AQR White Paper.

Jegadeesh, N., 1990. Predictable behavior of instrument returns. Journal of Finance, 54(6), 2143-2184.

Jegadeesh, N. and Titman, S., 1993. Returns to Buying Winners and Selling Losers: Implications for Stock Market Efficiency. Journal of Finance, 48(1), 65-91.

Jegadeesh, N. and Titman, S., 2002. Cross-Sectional and Time-Series Determinants of Momentum Returns. Review of Financial Studies, 15(1), 143-157.

Keim, D.B. and Stambaugh, R.F., 1986. Predicting returns in the stock and bond markets. Journal of Financial Economics, 17(2), 357-390.

Korajczyk, R. and Sadka, R., 2004. Are momentum profits robust to trading costs?. Journal of Finance, 59(3), 1039-1082.

Lehman, B.N., 1990. Fads, Martingales, and Market Efficiency. Quarterly Journal of Economics, 105(1), 1-28. 
Lesmond, D.A., Schill, M.J. and Zhou, C., 2004. The illusory nature of momentum profits. Journal of Financial Economics, 71(2), 349-380.

Levine, A. and Pedersen, L.H., 2016. Which trend is your friend? Financial Analysts Journal, 72(3), 51-66.

Liew, J. and Vassalou, M., 2000. Can book-to-market, size and momentum be risk factors that predict economic growth? Journal of Financial Economics, 57, 221-245.

Liu, L.X. and Zhang, L., 2008. Momentum Profits, Factor Pricing, and Macroeconomic Risk. Review of Financial Studies, 21(6), 2417 - 2448.

Moskowitz, T.J. and Grinblatt, M., 1999. Do Industries Explain Momentum? Journal of Finance, 54(4), 1249-1290.

Moskowitz, T.J., Ooi, Y.H. and Pedersen, L.H., 2012. Time-series momentum. Journal of Financial Economics, 104, 228-250.

Neely, C.J., Rapach, D.E., Tu, J. and Zhou, G., 2014. Forecasting the equity risk premium: the role of technical indicators. Management Science, 60(7), 1772-1791.

Novy-Marx, R., 2012. Is momentum really momentum? Journal of Financial Economics, 103, 429-453.

Novy-Marx, R. and Velikov, M., 2016. A taxonomy of anomalies and their trading costs. Review of Financial Studies, 29(1), 104-147.

Rouwenhorst, G.K., 1998. International Momentum Strategies. Journal of Finance, 53(1), 267-284.

Shleifer, A. and Summers, L.H., 1990. The noise trader approach to finance. Journal of Economic Perspectives, 4, 19-33.

Yao, Y., 2012. Momentum, contrarian, and the January seasonality. Journal of Banking and Finance, 36, 2757-2769. 


\section{Table 1: Returns of time-series momentum strategies}

At each month $t$ we calculate returns for individual equities from month $t-12$ to $t-2$. If the returns are positive, we define them as time-series winners; if the returns are negative, we define them as time-series losers. The TSMOM strategy goes long in a given stock if the sign is positive (winners) and short if it is negative (losers). The combined portfolio is held for month $t$. The table reports the a verage monthly returns (in percent), monthly returns in excess of the risk-free rate (in percent), volatilities (standard deviation, in percent), and Sharpe ratios of the winner, loser and combined winner-minus-loser (WML) portfolios. Skewness denotes the realized skew ness of the monthly returns to the portfolios. The market beta is estimated from regressing the time-series momentum returns on the value-weighted CRSP market index. The average number of stocks held in each portfolio and the average size of the stocks in the portfolio are also presented. $t$ values are reported between the parentheses. Statistical significance at the 1\%, 5\% and $10 \%$ levels is denoted by ***,** and *, respectively. Panels A, B and C report the results for the value-, volatility- and equal-weighted portfolios, respectively. The sample period is from January 1927 to September 2017.

\begin{tabular}{lccc}
\hline & Winner & Loser & WML \\
\cline { 2 - 4 }$\overline{\mathrm{r}}$ & \multicolumn{2}{c}{ Panel A: Value weighted } \\
$(t-$ value $)$ & 1.10 & 0.55 & 0.76 \\
$\overline{\mathrm{r}-\mathrm{r}_{\mathrm{f}}}$ & $(6.88)$ & $(2.98)$ & $(3.35)$ \\
$\sigma_{\overline{\mathrm{r}}}$ & 0.83 & 0.27 & 0.70 \\
$\sigma_{\overline{\mathrm{r}}-\mathrm{r}_{\mathrm{f}}}$ & 5.29 & 6.05 & 7.51 \\
Skewness & 5.30 & 6.06 & 7.50 \\
$\beta$ & 1.98 & 0.37 & -1.48 \\
Sharpe ratio & 0.92 & 1.04 & -0.43 \\
Mean size (in millions) & 0.16 & 0.04 & 0.09 \\
No. stocks & 1,287 & 569 & - \\
& 1464 & 1181 & \\
$\overline{\mathrm{r}}$ & \multicolumn{2}{c}{ Panel B: Volatility weighted } \\
$(t-$ value $)$ & 1.25 & 0.79 & 0.80 \\
$\overline{\mathrm{r}-\mathrm{r}_{\mathrm{f}}}$ & $(9.42)$ & $(4.45)$ & $(3.52)$ \\
$\sigma_{\overline{\mathrm{r}}}$ & 0.97 & 0.51 & 0.73 \\
$\sigma_{\overline{\mathrm{r}}-\mathrm{r}_{\mathrm{f}}}$ & 4.38 & 5.83 & 7.47 \\
Skewness & 4.39 & 5.84 & 7.45 \\
$\beta$ & -0.10 & 0.73 & -1.99 \\
Sharpe ratio & 0.73 & 0.97 & -0.47 \\
& 0.22 & 0.09 & 0.10 \\
$\overline{\mathrm{r}}$ & \multicolumn{3}{c}{ Panel C: Equalweighted } \\
$(\mathrm{t}-$ value $)$ & 1.53 & 0.96 & 0.86 \\
$\overline{\mathrm{r}-\mathrm{r}_{\mathrm{f}}}$ & $(7.65)$ & $(3.82)$ & $(2.78)$ \\
$\sigma_{\overline{\mathrm{r}}}$ & 1.25 & 0.68 & 0.80 \\
$\sigma_{\overline{\mathrm{r}}-\mathrm{r}_{\mathrm{f}}}$ & 6.60 & 8.29 & 10.19 \\
Skewness & 6.61 & 8.31 & 10.17 \\
$\beta$ & 1.74 & 1.75 & -3.02 \\
Sharpe ratio & 1.09 & 1.30 & -0.60 \\
\hline & 0.20 & 0.08 & 0.07 \\
\hline
\end{tabular}




\section{Table 2: Risk-adjusted returns to the time-series stock momentum strategy}

Estimated coefficients from CAPM, Fama-French three-factor model and Fama-French five-factor model regressions, where the dependent variable is the return on the time-series stock momentum (TSMOM) winner-minus-loser (WML) portfolio. MKT, SMB and HML represent the market, size and value premiums. RMW and CMA represent the profitability and investment premiums. Panels A, B and C present the regression results based on the value-, volatility- and equal-weighted WML portfolios, respectively. $t$-values, reported between parentheses, are adjusted for heteroskedasticity using White's heteroske dasticity-consistent estimator. All results are based on the sample period from January 1927 to Septe mber 2017, except for the FamaFrench five-factor alphas, which are estimated in the sample period from 1964 to September 2017 due to the availability of the returns of the RMW and CMA factors. $* * *, * *$ and $*$ denote statistical significance at the $1 \%, 5 \%$ and $10 \%$ levels, respectively.

\begin{tabular}{|c|c|c|c|c|c|c|c|c|c|}
\hline \multirow[t]{3}{*}{ Variable } & \multicolumn{9}{|c|}{$\mathrm{y}=\mathrm{WML}$ Portfolio } \\
\hline & \multicolumn{3}{|c|}{ Panel A: Value weighted } & \multicolumn{3}{|c|}{ Panel B: Volatility weighted } & \multicolumn{3}{|c|}{ Panel C: Equal weighted } \\
\hline & (1) & (2) & (3) & (4) & (5) & (6) & (7) & (8) & (9) \\
\hline Intercept & $\begin{array}{c}1.04 * * * \\
(4.81)\end{array}$ & $\begin{array}{c}1.15^{* * * *} \\
(5.24)\end{array}$ & $\begin{array}{l}0.49 * * \\
(1.98)\end{array}$ & $\begin{array}{c}1.11 * * * \\
(5.26)\end{array}$ & $\begin{array}{c}1.22 * * * \\
(5.79)\end{array}$ & $\begin{array}{c}0.61 * * * \\
(2.80)\end{array}$ & $\begin{array}{c}1.25 * * * \\
(4.54)\end{array}$ & $\begin{array}{c}1.43 * * * \\
(5.12)\end{array}$ & $\begin{array}{l}0.51^{*} \\
(1.79)\end{array}$ \\
\hline MKT & $\begin{array}{c}-0.43 * * * \\
(-3.30)\end{array}$ & $\begin{array}{c}-0.39 * * * \\
(-3.54)\end{array}$ & $\begin{array}{l}-0.10 \\
(-0.95)\end{array}$ & $\begin{array}{c}-0.47 * * * \\
(-3.56)\end{array}$ & $\begin{array}{c}-0.41 * * * \\
(-3.89)\end{array}$ & $\begin{array}{c}-0.09 \\
(-0.96)\end{array}$ & $\begin{array}{c}-0.60 * * * \\
(-3.19)\end{array}$ & $\begin{array}{c}-0.51 * * * \\
(-3.77)\end{array}$ & $\begin{array}{l}-0.06 \\
(-0.93)\end{array}$ \\
\hline SMB & & $\begin{array}{c}0.11 \\
(0.88)\end{array}$ & $\begin{array}{c}0.00 \\
(0.01)\end{array}$ & & $\begin{array}{c}0.01 \\
(0.11)\end{array}$ & $\begin{array}{l}-0.14 \\
(-1.29)\end{array}$ & & $\begin{array}{c}0.04 \\
(0.24)\end{array}$ & $\begin{array}{l}-0.08 \\
(-0.84)\end{array}$ \\
\hline HML & & $\begin{array}{c}-0.41 * * \\
(-2.44)\end{array}$ & $\begin{array}{c}-0.45^{* * * *} \\
(-2.69)\end{array}$ & & $\begin{array}{c}-0.41 * * \\
(-2.44)\end{array}$ & $\begin{array}{l}-0.40 * * \\
(-2.56)\end{array}$ & & $\begin{array}{c}-0.62^{* *} \\
(-2.36)\end{array}$ & $\begin{array}{c}-0.65 * * * \\
(-4.88)\end{array}$ \\
\hline RMW & & & $\begin{array}{c}0.12 \\
(0.83)\end{array}$ & & & $\begin{array}{c}0.15 \\
(1.34)\end{array}$ & & & $\begin{array}{l}0.32 * * \\
(2.44)\end{array}$ \\
\hline CMA & & & $\begin{array}{c}0.66^{* * * *} \\
(3.06)\end{array}$ & & & $\begin{array}{c}0.66^{* * *} \\
(3.48)\end{array}$ & & & $\begin{array}{c}1.08^{* * *} \\
(5.43)\end{array}$ \\
\hline Adj. $R^{2}$ & $9 \%$ & $12 \%$ & $4 \%$ & $11 \%$ & $15 \%$ & $7 \%$ & $9 \%$ & $14 \%$ & $6 \%$ \\
\hline
\end{tabular}




\section{Table 3: Time-series stock momentum: Sorting by size}

Each month, we use the $30^{\text {th }}$ - and $70^{\text {th }}$ - percentile NYSE break-points to allocate all stocks in the sample into three groups: Small, Medium and Large. Within each size group we implement the time-series momentum strategy. Panel A reports the summary statistics of the winner-minus-loser (WML) portfolios constructed within each size group. Panels B, C and D present the raw returns and CAPM, Fama-French three-factor (FF3) and Fama-French five-factor (FF5) alphas for the WML portfolios using value-, volatility- and equal-weighting, respectively. All results are based on the sample period from January 1927 to September 2017, except for the Fama-French fivefactor alphas, which are estimated in the sample period from January 1964 to September 2017 due to the availability of the returns of the RMW and CMA factors. ***, ** and * denote statistical significance at the $1 \%, 5 \%$ and $10 \%$ levels, respectively.

Size class (NYSE break-points)

\begin{tabular}{|c|c|c|c|}
\hline & Small & Medium & Large \\
\hline \multicolumn{4}{|c|}{ Panel A: Summary statistics } \\
\hline No. stocks & 1,748 & 620 & 349 \\
\hline$\%$ of stocks & $64 \%$ & $23 \%$ & $13 \%$ \\
\hline Total market cap, $\$ 10^{9}$ & 155 & 490 & 3,335 \\
\hline$\%$ of market cap & $4 \%$ & $12 \%$ & $84 \%$ \\
\hline Firm size, $\$ 10^{6^{1}}$ & 59 & 533 & 6,591 \\
\hline \multicolumn{4}{|l|}{ Panel B: Value weighted } \\
\hline Raw & $\begin{array}{c}0.76^{* *} \\
(2.00)\end{array}$ & $\begin{array}{c}1.07 * * * \\
(3.58)\end{array}$ & $\begin{array}{c}1.09 * * * * \\
(4.33)\end{array}$ \\
\hline CAPM & $\begin{array}{c}1.41 * * * \\
(4.53)\end{array}$ & $\begin{array}{c}1.31 * * * \\
(4.58)\end{array}$ & $\begin{array}{c}1.13 * * * \\
(4.79)\end{array}$ \\
\hline FF3 & $\begin{array}{c}1.65^{* * *} \\
(5.34)\end{array}$ & $\begin{array}{c}1.47 * * * \\
(5.18)\end{array}$ & $\begin{array}{c}1.28 * * * \\
(5.47)\end{array}$ \\
\hline FF5 & $\begin{array}{c}0.78^{* *} \\
(2.33)\end{array}$ & $\begin{array}{l}0.59^{*} \\
(1.95)\end{array}$ & $\begin{array}{c}0.59 * * \\
(2.30)\end{array}$ \\
\hline \multicolumn{4}{|c|}{ Panel C: Volatility weighted } \\
\hline Raw & $\begin{array}{l}0.68^{* *} \\
(1.98)\end{array}$ & $\begin{array}{c}1.31 * * * \\
(3.87)\end{array}$ & $\begin{array}{c}1.01 * * * \\
(4.74)\end{array}$ \\
\hline CAPM & $\begin{array}{c}1.30^{* * *} \\
(4.21)\end{array}$ & $\begin{array}{c}1.19 * * * \\
(4.91)\end{array}$ & $\begin{array}{c}1.07 * * * \\
(4.97)\end{array}$ \\
\hline FF3 & $\begin{array}{c}1.53^{* * * *} \\
(5.66)\end{array}$ & $\begin{array}{c}1.32 * * * \\
(5.45)\end{array}$ & $\begin{array}{c}1.20 * * * \\
(5.62)\end{array}$ \\
\hline FF5 & $\begin{array}{c}0.75^{* *} \\
(3.13)\end{array}$ & $\begin{array}{c}0.52 * * \\
(2.15)\end{array}$ & $\begin{array}{c}0.51 * * \\
(2.23)\end{array}$ \\
\hline \multicolumn{4}{|l|}{ Panel D: Equal weighted } \\
\hline Raw & $\begin{array}{c}0.58 \\
(1.46)\end{array}$ & $\begin{array}{c}1.10^{* * * *} \\
(3.58)\end{array}$ & $\begin{array}{c}1.11 \text { *** } \\
(4.24)\end{array}$ \\
\hline CAPM & $\begin{array}{c}1.23 * * * \\
(3.81)\end{array}$ & $\begin{array}{c}1.35^{* * * *} \\
(4.61)\end{array}$ & $\begin{array}{c}1.20 * * * \\
(4.61)\end{array}$ \\
\hline FF3 & $\begin{array}{c}1.50^{* * * *} \\
(4.66)\end{array}$ & $\begin{array}{c}1.52^{* * * *} \\
(5.23)\end{array}$ & $\begin{array}{c}1.37 * * * \\
(5.33)\end{array}$ \\
\hline FF5 & $\begin{array}{c}0.50 \\
(1.40) \\
\end{array}$ & $\begin{array}{c}0.60 * * \\
(1.97) \\
\end{array}$ & $\begin{array}{c}0.59 * * \\
(2.21) \\
\end{array}$ \\
\hline
\end{tabular}




\section{Table 4: Macroeconomic risk exposure}

Estimated coefficients from regressions in which the dependent variable is the winner-minusloser portfolio return. The independent variables include the following: Dividend yield (DIV), measure $\mathrm{as}$ the total dividend payments accruing to the CRSP value-weighted index, divided by the current level of the index; the yield on the three-month Treasury bills (YLD); the term spread (TERM), measure as the difference between the average yield of 20-year Treasury bonds and the yield of 1-year Treasury bonds; default spread (DEF), measured as the difference between the average yield of bonds rated Baa by Moody's and the average yield of bonds rated Aaa by Moody's; and the growth rate of the gross domestic product (GDP). The sample period is from January 1951 to September 2017, due to the availability of the macroeconomic variables. $t$ statistics, reported in parentheses, are adjusted for heteroskedasticity using White's heteroskedasticity-consistent estimator. $* * * * *$ and $*$ denote statistical significance at the $1 \%$, $5 \%$ and $10 \%$ levels, respectively.

\begin{tabular}{lcccc}
\hline & \multicolumn{3}{c}{ Dependent variable: WML } \\
\cline { 3 - 5 } Independent & Intercept & $1.18^{*}$ & $1.00^{*}$ & Equal-weighted \\
variables & & $(1.80)$ & $(1.70)$ & 1.26 \\
& DIV & 0.10 & 0.03 & 0.08 \\
& & $(0.66)$ & $0.28)$ & $(0.47)$ \\
& YLD & -0.01 & 0.05 & 0.09 \\
& & $(-0.21)$ & $(0.88)$ & $(1.07)$ \\
& TERM & -0.13 & -0.15 & -0.22 \\
& & $(-0.60)$ & $(-0.76)$ & $(-0.81)$ \\
& DEF & $-0.93^{* *}$ & $-0.90^{* *}$ & $-1.46^{* *}$ \\
& & $(-1.99)$ & $(-2.15)$ & $(-2.50)$ \\
& GDP & 0.48 & $0.98^{*}$ & 1.15 \\
& \multirow{2}{*}{ Adj. $\mathrm{R}^{2}$} & $(0.77)$ & $(1.76)$ & $(1.48)$ \\
& & $0.20 \%$ & $0.79 \%$ & $0.91 \%$ \\
\hline
\end{tabular}




\section{Table 5: Time-series momentum and market state}

This table reports returns of the winner-minus-loser (WML) portfolios conditional on the market state. We define the market state by sorting monthly excess returns for the market portfolio (Mkt-Ret) into deciles. Each month is assigned a number from 1 (lowest excess returns) to 10 (highest excess returns). In Panel A, the market proxy is the S\&P 500 index and in Panel B, the market proxy is the CRSP value-weighted index. The sample period runs from January 1927 to September 2017. Average monthly WML returns and $t$ statistics are reported for each contemporaneous market excess return ranking. $* * *, * *$ and $*$ denote statistical significance at the $1 \%, 5 \%$ and $10 \%$ levels, respectively.

\begin{tabular}{|c|c|c|c|c|c|c|c|c|c|c|c|c|}
\hline \multirow{3}{*}{$\begin{array}{c}\text { Mkt-Ret } \\
\text { rank }\end{array}$} & \multicolumn{6}{|c|}{ Panel A: S\&P returns proxy for the market } & \multicolumn{6}{|c|}{ Panel B: CRSP value-weighted returns proxy for the market } \\
\hline & \multicolumn{2}{|c|}{ Value weighted } & \multicolumn{2}{|c|}{ Volatility weighted } & \multicolumn{2}{|c|}{ Equal weighted } & \multicolumn{2}{|c|}{ Value weighted } & \multicolumn{2}{|c|}{ Volatility weighted } & \multicolumn{2}{|c|}{ Equal weighted } \\
\hline & Mean & $t$-value & Mean & $t$-value & Mean & $t$-value & Mean & $t$-value & Mean & $t$-value & Mean & $t$-value \\
\hline 1 (Low) & $3.07 * *$ & $(2.41)$ & $3.20^{* * *}$ & $(2.61)$ & $3.33 * *$ & $(2.19)$ & $3.38^{* * *}$ & $(2.65)$ & $3.36^{* * * *}$ & $(2.73)$ & $3.44 * *$ & $(2.24)$ \\
\hline 2 & -0.13 & $(-0.30)$ & 0.49 & $(1.23)$ & 0.49 & $(0.83)$ & -0.44 & $(-1.10)$ & 0.38 & $(1.01)$ & 0.25 & $(0.46)$ \\
\hline 3 & 0.34 & $(1.20)$ & $0.73^{* * *}$ & $(2.80)$ & $0.70^{*}$ & $(1.78)$ & 0.24 & $(0.92)$ & $0.66^{* *}$ & $(2.48)$ & $0.83 * *$ & $(2.04)$ \\
\hline 4 & $0.63 * * *$ & $(2.90)$ & $0.77 * * *$ & $(3.31)$ & $1.14 * * *$ & $(3.13)$ & $0.57 * * *$ & (3.03) & $0.63 * * *$ & $(3.77)$ & $0.84 * * *$ & $(3.75)$ \\
\hline 6 & $1.40 * * *$ & $(6.96)$ & $1.54 * * *$ & $(6.76)$ & $2.14 * * *$ & $(6.54)$ & $1.51 * * *$ & (7.11) & $1.45^{* * *}$ & $(6.21)$ & $1.99 * * *$ & $(6.63)$ \\
\hline 7 & 1.59 *** & $(4.75)$ & $1.43^{* * *}$ & (4.37) & $1.58 * * *$ & $(2.80)$ & $1.50 * * *$ & (5.44) & $1.36^{* * *}$ & $(5.12)$ & $1.74 * * *$ & $(4.29)$ \\
\hline 8 & 0.38 & $(0.79)$ & 0.41 & $(0.88)$ & 0.50 & $(0.78)$ & $1.35^{* * *}$ & (3.16) & $1.32 * * *$ & $(3.42)$ & $1.73 * * *$ & $(2.80)$ \\
\hline 9 & $1.68 * * *$ & $(2.88)$ & $1.24 * *$ & $(2.21)$ & $1.39 *$ & $(1.83)$ & 0.55 & $(0.83)$ & 0.30 & $(0.46)$ & 0.19 & $(0.22)$ \\
\hline 10 (High) & -2.25 & $(-1.45)$ & $-2.69 *$ & $(-1.70)$ & $-3.87 *$ & $(-1.74)$ & -1.81 & $(-1.16)$ & -2.39 & $(-1.50)$ & -3.51 & $(-1.57)$ \\
\hline
\end{tabular}




\section{Table 6: Time-series stock momentum and information discreteness}

This table reports average returns and alphas of portfolios of stocks double-sorted on formation-period returns (PRET) and information discreteness (ID). PRET is the prior 11-month return, with the most recent month $t-1$ skipped. ID is defined as sign(PRET) $\times[\%$ neg - \%pos], where \%neg and \%pos denote the respective percentages of negative and positive daily returns over the prior 11-month period. We require ten nonzero daily observations on a verage across the 11-month formation period. Low values of ID correspond to discrete information, and high values to continuous information. The raw returns and CAPM, Fama-French three-factor (FF3) and Fama-French five-factor (FF5) alphas correspond to the value-weighted winner-minus-loser TSMOM portfolios over one-month holding periods. Panel A reports the results based on sequential double-sorting, by PRET quintiles and then by ID quintiles. Panel B presents the results based on independent sorting. $t$-values, reported between parentheses, are adjusted for heteroskedasticity using White's heteroskedasticity-consistent estimator. All results are based on the sample period from January 1927 to September 2017, except for Fama-French five-factor alphas, which are estimated in the sample period from 1964 to September 2017 due to the availability of the returns of the RMW and CMA factors.

\begin{tabular}{|c|c|c|c|c|c|c|c|c|c|c|c|c|}
\hline \multirow[b]{2}{*}{ ID } & \multirow[b]{2}{*}{ Winner } & \multirow[b]{2}{*}{$t$-value } & \multirow[b]{2}{*}{ Loser } & \multirow[b]{2}{*}{$t$-value } & \multicolumn{2}{|c|}{ Raw } & \multicolumn{2}{|c|}{ CAPM } & \multicolumn{2}{|c|}{ FF3 } & \multicolumn{2}{|c|}{ FF5 } \\
\hline & & & & & Returns & $t$-value & Alpha & $t$-value & Alpha & $t$-value & Alpha & $t$-value \\
\hline Discrete & 1.13 & $(3.35)$ & 0.59 & $(3.33)$ & 0.50 & $(2.17)$ & 0.64 & $(2.71)$ & 0.64 & $(2.75)$ & -0.06 & $(-0.26)$ \\
\hline 3 & 0.99 & $(6.35)$ & 0.60 & (2.99) & 0.72 & (2.93) & 1.02 & (4.29) & 1.13 & $(4.70)$ & 0.35 & (1.39) \\
\hline 4 & 1.09 & (7.18) & 0.39 & $(1.80)$ & 0.93 & $(3.50)$ & 1.28 & (5.19) & 1.42 & (5.74) & 0.71 & $(2.53)$ \\
\hline Continuous & 1.09 & $(7.32)$ & 0.21 & $(0.89)$ & 1.15 & (4.09) & 1.56 & (5.91) & 1.73 & $(6.56)$ & 0.98 & $(2.83)$ \\
\hline 2 & 1.01 & $(6.63)$ & 0.69 & (3.53) & 0.82 & $(3.23)$ & 0.86 & $(3.29)$ & 0.96 & $(3.66)$ & 0.40 & (1.59) \\
\hline 3 & 1.04 & $(6.55)$ & 0.53 & $(2.79)$ & 0.69 & $(2.60)$ & 1.02 & $(4.00)$ & 1.13 & $(4.45)$ & 0.44 & $(1.55)$ \\
\hline 4 & 1.13 & $(7.57)$ & 0.58 & $(2.79)$ & 0.61 & $(2.03)$ & 1.23 & (4.89) & 1.35 & $(5.33)$ & 0.52 & (1.69) \\
\hline Continuous & 1.24 & $(8.09)$ & 0.19 & $(0.87)$ & 0.86 & $(2.54)$ & 1.69 & $(6.35)$ & 1.81 & $(6.75)$ & 0.83 & $(2.14)$ \\
\hline
\end{tabular}




\section{Table 7: Time-series stock momentum and investors' sentiment}

This table reports the value-weighted monthly returns of the time-series stock momentum strategy conditional on the investor-sentiment state. The states are determined by a weighted rolling average of the aligned investor sentiment index of Huang et al. (2015) that is extracted from Baker and Wurgler's (2006) six individual investor sentiment proxies. To calculate the weighted rolling average, we multiply the sentiment index by 3 in the prior month, by 2 in the month 2 months prior and by 1 in the month 3 months prior. The top $30 \%$ of the resulting weighted rolling average time series is classified as Optimistic, the middle $40 \%$ as Mild and the bottom 30\% as Pessimistic. $t$-values, reported between parentheses, are adjusted for heteroskedasticity using White's heteroskedasticity-consistent estimator. Due to the availability of the aligned investor sentiment index, the sample period starts from September 1965 to December 2014.

\begin{tabular}{|c|c|c|c|c|c|c|c|c|c|c|c|c|}
\hline \multirow[b]{2}{*}{ ID } & \multirow[b]{2}{*}{ Winner } & \multirow[b]{2}{*}{$t$-value } & \multirow[b]{2}{*}{ Loser } & \multirow[b]{2}{*}{$t$-value } & \multicolumn{2}{|c|}{ Raw } & \multicolumn{2}{|c|}{ CAPM } & \multicolumn{2}{|c|}{ FF3 } & \multicolumn{2}{|c|}{ FF5 } \\
\hline & & & & & Returns & $t$-value & Alpha & $t$-value & Alpha & $t$-value & Alpha & $t$-value \\
\hline Mild & 1.18 & $(4.08)$ & 0.59 & (1.77) & 0.49 & $(1.54)$ & 0.53 & (1.64) & 0.58 & $(1.75)$ & 0.76 & $(2.24)$ \\
\hline
\end{tabular}




\section{Table 8: Time-series momentum vs. cross-sectional momentum}

Estimated coefficients from regressing non-dollar-neutral and dollar-neutral time-series stock momentum (TSMOM) returns on the Fama-French-Carhart four factors: MKT, SMB, HML and UMD, where UMD represents cross-sectional momentum. The non-dollar-neutral portfolio is as defined in Table 1. The dollar-neutral portfolio weights the winner portfolio to have the same dollar value as the loser portfolio. Panels A, B and C report the results for the value-, volatilityand equal-weighted strategies, respectively. The sample period is from January 1927 to September 2017. The $t$-values, reported between parentheses, are adjusted for heteroskedasticity using White's heteroskedasticity-consistent estimator. Statistical significance at the $1 \%, 5 \%$ and $10 \%$ levels is denoted by $* * *, * *$ and $*$, respectively.

\begin{tabular}{lcccccc}
\hline & \multicolumn{2}{c}{ Panel A: $V W$} & \multicolumn{2}{c}{ Panel B: VolW } & \multicolumn{2}{c}{ Panel C: $E W$} \\
\cline { 2 - 7 } & $\begin{array}{l}\text { Non- } \\
\text { dollar } \\
\text { neutral }\end{array}$ & $\begin{array}{l}\text { Dollar- } \\
\text { neutral }\end{array}$ & $\begin{array}{l}\text { Non- } \\
\text { dollar } \\
\text { neutral }\end{array}$ & $\begin{array}{l}\text { Dollar- } \\
\text { neutral }\end{array}$ & $\begin{array}{l}\text { Non- } \\
\text { dollar } \\
\text { neutral }\end{array}$ & $\begin{array}{c}\text { Dollar- } \\
\text { neutral }\end{array}$ \\
\cline { 2 - 7 } Intercept & $(1)$ & $(2)$ & $(3)$ & $(4)$ & $(5)$ & $(6)$ \\
MKT & -0.09 & $0.22^{* * *}$ & 0.07 & $0.26^{* * *}$ & -0.26 & $0.26^{* * *}$ \\
& $(-0.53)$ & $(2.70)$ & $(0.44)$ & $(5.24)$ & $(-1.24)$ & $(3.01)$ \\
SMB & -0.11 & 0.02 & $-0.16^{* *}$ & $-0.07 * * *$ & $-0.14 *$ & -0.01 \\
& $(-1.54)$ & $(0.42)$ & $(-2.16)$ & $(-4.03)$ & $(-1.74)$ & $(-0.45)$ \\
HML & $0.15^{* *}$ & $-0.13^{*}$ & 0.05 & $-0.17^{* * *}$ & 0.09 & $-0.24^{* * * *}$ \\
& $(2.05)$ & $(-1.70)$ & $(0.65)$ & $(-5.41)$ & $(0.90)$ & $(-5.71)$ \\
UMD & $0.18^{* *}$ & 0.15 & 0.13 & -0.02 & 0.18 & 0.03 \\
& $(2.41)$ & $(1.47)$ & $(1.55)$ & $(-0.63)$ & $(1.47)$ & $(0.54)$ \\
Adj. $\mathrm{R}^{2}$ & $1.25^{* * *}$ & $0.46^{* * *}$ & $1.16^{* * *}$ & $0.44^{* * *}$ & $1.70 * * *$ & $0.55^{* * *}$ \\
& $(18.88)$ & $(7.24)$ & $(17.26)$ & $(24.32)$ & $(17.26)$ & $(7.92)$ \\
\hline
\end{tabular}




\section{Table 9: Revised time-series momentum}

For the revised time-series momentum (RTSMOM) strategy, at each month $t$, we limit the sample to stocks whose cumulative returns from month $t-12$ to $t-2$ are larger than one standard deviation, measured over months $t-23$ to $t-13$, in absolute value. We then construct winnerminus-loser portfolios from this subsample. Panel A presents summary statistics for the valueweighted RTSMOM strategy. Panel B presents regression results for RTSMOM returns on the CAPM, the Fama-French three factors and the Fama-French five factors. Panel $\mathrm{C}$ reports the results of the difference tests between RTSMOM and TSMOM strategies. Statistical significance at the $1 \%, 5 \%$ and $10 \%$ levels is denoted by $* * *, * *$ and $*$, respectively. $t$-values, reported between parentheses, are adjusted for heteroskedasticity using White's heteroskedasticityconsistent estimator. All results are based on the sample period from January 1927 to September 2017, except for Fama-French five-factor alphas, which are estimated in the sample period from 1964 to September 2017 due to the availability of the returns of the RMW and CMA factors.

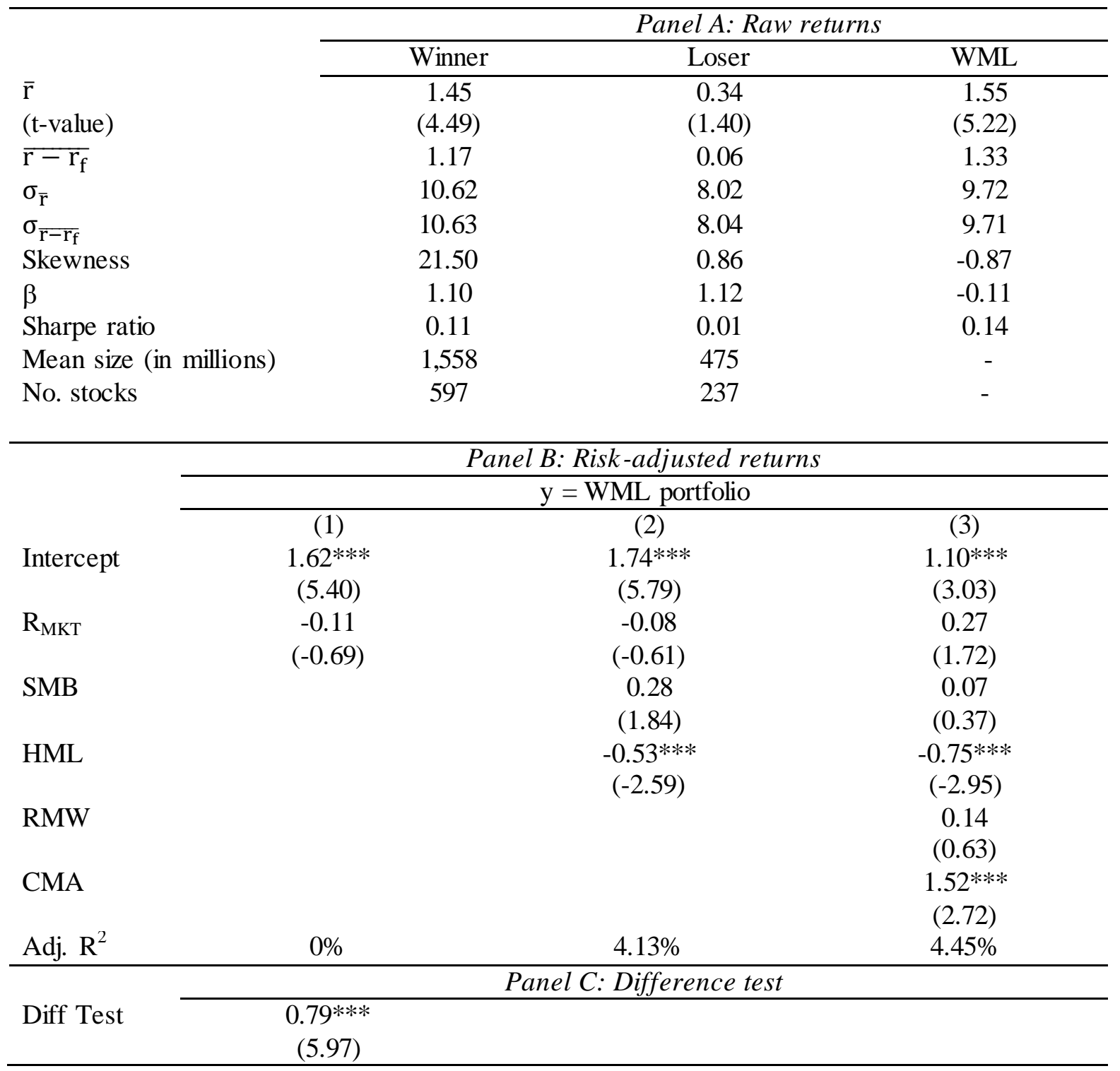




\section{Table 10: Dual momentum}

The dual momentum strategy sequentially double-sorts stocks, first on the TSMOM measure and then on the CSMOM measure. Each month, we assign stocks to the time-series loser (T1) group if their prior 11-month returns are ne gative, and to the time-series winner (T2) group if the ir prior 11-month returns are positive. Within the two time-series momentum groups, stocks are ranked into quintiles based on the prior 11-month returns, with P1 stocks being the worst-performing $20 \%$ and P5 stocks being the best-performing 20\%. The dual momentum strate gy buys the valueweighted, strongest winner portfolio (T2 and P5) and sells the value-weighted weakest loser portfolio (T1 and P1) in a zero net-investment strategy. Panel A reports summary statistics. Panel B presents the regression results for dual momentum WML returns based on the CAPM, FamaFrench three-factor model and Fama-French five-factor model. Panel $\mathrm{C}$ reports the results of difference tests. DiffTest(TSMOM) is the difference test between dual momentum and timeseries stock momentum; DiffTest(CSMOM) is the difference test between dual momentum and cross-sectional stock momentum. Statistical significance at the $1 \%, 5 \%$ and $10 \%$ levels is denoted by ***, ** and *, respectively. All results are based on the sample period from January 1927 to September 2017, except for Fama-French five-factor model coefficients, which are estimated in the sample period from 1964 to September 2017, due to the availability of the returns of the RMW and CMA factors.

\begin{tabular}{lccc}
\hline & \multicolumn{3}{c}{ Panel A: Raw returns } \\
\cline { 2 - 4 } & Winner & Loser & WML \\
\cline { 2 - 4 }$(\mathrm{r}$ & 1.81 & -0.11 & 1.74 \\
$(\mathrm{t}-$ value $)$ & $(5.12)$ & $(-0.36)$ & $(3.85)$ \\
$\overline{\mathrm{r}-\mathrm{r}_{\mathrm{f}}}$ & 1.54 & -0.39 & 1.68 \\
$\sigma_{\overline{\mathrm{r}}}$ & 11.69 & 10.93 & 14.96 \\
$\sigma_{\overline{\mathrm{r}}-\mathrm{r}_{\mathrm{f}}}$ & 11.70 & 10.95 & 14.95 \\
Skewness & 16.49 & 1.11 & -2.69 \\
$\beta$ & 1.37 & 1.66 & -1.02 \\
Sharpe ratio & 0.14 & -0.03 & 0.17 \\
Mean size (in millions) & 697 & 85 & - \\
No. stocks & 290 & 229 & -
\end{tabular}

\begin{tabular}{|c|c|c|c|}
\hline & \multicolumn{3}{|c|}{ Panel B: Risk-adjusted returns } \\
\hline & \multicolumn{3}{|c|}{$\mathrm{y}=\mathrm{WML}$ portfolio } \\
\hline & (1) & (2) & (3) \\
\hline Intercept & $2.41 * * *$ & $2.72 * * *$ & $1.70 * * *$ \\
\hline & $(6.01)$ & $(6.42)$ & $(3.34)$ \\
\hline $\mathrm{R}_{\mathrm{MKT}}$ & $-1.02 * * *$ & $-0.85^{* * *}$ & $-0.34^{*}$ \\
\hline & $(-4.20)$ & $(-4.73)$ & $(-1.90)$ \\
\hline SMB & & 0.02 & 0.08 \\
\hline & & $(0.09)$ & $(0.31)$ \\
\hline HML & & $-1.08 * * *$ & $-1.27 * * *$ \\
\hline & & $(-3.20)$ & $(-3.35)$ \\
\hline RMW & & & $\begin{array}{l}0.82 * * \\
(2.35)\end{array}$ \\
\hline CMA & & & $\begin{array}{c}1.52 * * * \\
(3.05)\end{array}$ \\
\hline Adj. $R^{2}$ & $13.27 \%$ & $19.14 \%$ & $8.43 \%$ \\
\hline & & : Differen & \\
\hline $\begin{array}{l}\text { Diff Test } \\
\text { (TSMOM) } \\
\text { Diff Test } \\
\text { (CSMOM) }\end{array}$ & $\begin{array}{c}0.98^{* * *} \\
(3.65) \\
0.82^{* * *} \\
(2.88)\end{array}$ & & \\
\hline
\end{tabular}




\section{Table 11: TSMOM with transaction costs}

The table reports TSMOM turnover, value-weighted WML gross and net returns and alphas using WML net returns. Transaction costs are estimated by using monthly turnover ratios to be multiplied by one percent, as suggested by Novy-Marx and Velikov (2016). Each panel corresponds to the given strategy: time-series momentum, revised time-series momentum and dual momentum. Each row of a panel corresponds to the given turnover ratio calculation. $\operatorname{Min}(\mathrm{SEC})$ is the lesser of purchases or sales, divided by the average of portfolio assets. Max is the maximum of purchases or sales, divided by the average of portfolio assets. Statistical significance at the $1 \%, 5 \%$ and $10 \%$ levels is denoted by $* * *$, ** and *, respectively. $t$-values, reported between parentheses, are adjusted for heteroskedasticity using White's heteroskedasticity-consistent estimator. All results are based on the sample period from January 1927 to September 2017, except for Fama-French five-factor alphas, which are estimated in the sample period from 1964 to September 2017 due to the availability of the returns of the RMW and CMA factors.

\begin{tabular}{|c|c|c|c|c|c|c|c|c|c|c|c|c|}
\hline & \multicolumn{2}{|c|}{ Turnover } & \multicolumn{2}{|c|}{ Gross returns } & \multicolumn{2}{|c|}{ Net returns } & \multicolumn{2}{|c|}{ CAPM (net) } & \multicolumn{2}{|c|}{ FF3 (net) } & \multicolumn{2}{|c|}{ FF5 (net) } \\
\hline & Winner & Loser & Returns & $t$-value & Returns & $t$-value & Alpha & $t$-value & Alpha & $t$-value & Alpha & $t$-value \\
\hline \multicolumn{13}{|c|}{ Panel A: Time-series momentum } \\
\hline $\operatorname{Min}(\mathrm{SEC})$ & $6 \%$ & $12 \%$ & $0.76 * * *$ & $(3.35)$ & $0.63 * * *$ & $(2.75)$ & $0.91 * * *$ & $(4.17)$ & $1.01 * * *$ & $(4.61)$ & 0.34 & $(1.36)$ \\
\hline Max & $22 \%$ & $40 \%$ & $0.76 * * *$ & $(3.35)$ & 0.31 & $(1.37)$ & $0.60 * * *$ & $(2.73)$ & $0.70 * * *$ & $(3.17)$ & 0.06 & $(0.23)$ \\
\hline \multicolumn{13}{|c|}{ Panel B: Revised time-series momentum } \\
\hline $\operatorname{Min}(\mathrm{SEC})$ & $11 \%$ & $18 \%$ & $1.55^{* * *}$ & $(5.22)$ & $1.28 * * *$ & $(4.36)$ & $1.33 * * *$ & $(4.53)$ & $1.47 * * *$ & $(4.97)$ & $0.86^{* *}$ & $(2.36)$ \\
\hline Max & $40 \%$ & $60 \%$ & $1.55 * * *$ & $(5.22)$ & $0.71 * *$ & $(2.42)$ & $0.76 * * *$ & $(2.60)$ & $0.90 * * *$ & $(3.04)$ & 0.36 & $(0.99)$ \\
\hline \multicolumn{13}{|c|}{ Panel C: Dual momentum } \\
\hline $\operatorname{Min}(\mathrm{SEC})$ & $22 \%$ & $23 \%$ & $1.74 * * *$ & $(3.85)$ & $1.22 * * *$ & $(2.70)$ & $1.89 * * *$ & $(4.78)$ & $2.22 * * *$ & $(5.54)$ & $1.26 * *$ & $(2.42)$ \\
\hline Max & $43 \%$ & $52 \%$ & $1.74 * * *$ & $(3.85)$ & $0.82 *$ & $(1.81)$ & $1.49 * * *$ & $(3.76)$ & $1.82 * * *$ & $(4.52)$ & $0.89 *$ & $(1.71)$ \\
\hline
\end{tabular}




\section{Table 12: Time-series momentum and aggregate momentum}

Coefficient estimates from regressing time-series momentum and aggre gate momentum on each other. TSMOM is the return on the time-series momentum WML portfolio. AGMOM is the month $t$ return on the S\&P 500 if its month $t-1$ value is higher than its month $t-12$ value; otherwise, AGMOM is the negative of the month $t$ return. Panels A, B and C report the results of regressing value-, volatility- and equal-weighted TSMOM on AGMOM, respectively. Statistical significance at the $1 \%, 5 \%$ and $10 \%$ levels is denoted by $* * *, * *$ and $*$, respectively. $t$-values, reported between parentheses, are adjusted for heteroskedasticity using White's heteroskedasticity-consistent estimator. The investment period is from January 1927 to September 2017.

\begin{tabular}{|c|c|c|c|c|c|}
\hline & & Intercept & AGMOM & TSMOM & $\mathrm{R}^{2}$ \\
\hline & \multicolumn{5}{|c|}{ Panel A: Value weighted } \\
\hline TSMOM & $\begin{array}{l}\text { Coefficient } \\
(t \text {-Stat })\end{array}$ & $\begin{array}{l}0.33 * * \\
(2.27)\end{array}$ & $\begin{array}{l}1.09 * * * \\
(15.86)\end{array}$ & & $63 \%$ \\
\hline \multirow[t]{2}{*}{ AGMOM } & $\begin{array}{l}\text { Coefficient } \\
(t-\text { Stat })\end{array}$ & $\begin{array}{l}-0.04 \\
(-0.42)\end{array}$ & & $\begin{array}{c}0.57 * * * \\
(30.36)\end{array}$ & $63 \%$ \\
\hline & \multicolumn{5}{|c|}{ Panel B: Volatility weighted } \\
\hline TSMOM & $\begin{array}{l}\text { Coefficient } \\
(t \text {-Stat })\end{array}$ & $\begin{array}{l}0.38^{* * *} \\
(2.45)\end{array}$ & $\begin{array}{l}1.05^{* * * *} \\
(13.60)\end{array}$ & & $58 \%$ \\
\hline \multirow[t]{2}{*}{ AGMOM } & $\begin{array}{l}\text { Coefficient } \\
(t \text {-Stat })\end{array}$ & $\begin{array}{l}-0.05 \\
(-0.46)\end{array}$ & & $\begin{array}{c}0.56^{* * * *} \\
(26.48)\end{array}$ & $58 \%$ \\
\hline & \multicolumn{5}{|c|}{ Panel C: Equal weighted } \\
\hline TSMOM & $\begin{array}{l}\text { Coefficient } \\
(t-\text { Stat })\end{array}$ & $\begin{array}{c}0.32 \\
(1.37)\end{array}$ & $\begin{array}{l}1.37 * * * \\
(11.32)\end{array}$ & & $54 \%$ \\
\hline AGMOM & $\begin{array}{l}\text { Coefficient } \\
(t \text {-Stat) }\end{array}$ & $\begin{array}{c}0.06 \\
(0.49)\end{array}$ & & $\begin{array}{c}0.39 * * * \\
(17.11)\end{array}$ & $54 \%$ \\
\hline
\end{tabular}




\section{Table 13: Time-series stock momentum in international equity markets}

Panel A reports raw returns and alphas (in percentages) of the time-series stock momentum strategy in 13 international equity markets. Alpha is the intercept from CAPM and Fama-French three-factor model (FF3) regressions in which the dependent variable is the return of the value-weighted WML portfolio in the given country/region. Panel B reports the raw returns and alphas of the joint tests of the TSMOM, revised TSMOM, and dual momentum strategies in European countries, Northern American countries and all countries. The risk factors used in the CAPM and the FF3 are European risk factors for all European countries, North American risk factors for all North American countries and global risk factors for all countries, with the availability from July 1990 to September 2017. $t$-values, reported between parentheses, are adjusted for heteroskedasticity using White's heteroskedasticity-consistent estimator. Statistical significance at the $1 \%, 5 \%$ and $10 \%$ levels is denoted by ***, ** and *, respectively.

\begin{tabular}{|c|c|c|c|c|c|c|c|c|c|}
\hline \multirow[b]{2}{*}{ Countries } & \multirow{2}{*}{$\begin{array}{c}\text { Data } \\
\text { start year }\end{array}$} & \multicolumn{2}{|c|}{ Whole sample } & \multicolumn{2}{|c|}{$07 / 90-09 / 17$} & \multicolumn{2}{|c|}{ CAPM } & \multicolumn{2}{|c|}{ FF3 } \\
\hline & & Returns & $t$-value & Returns & $t$-value & Alpha & $t$-value & Alpha & $t$-value \\
\hline & \multicolumn{9}{|c|}{ Panel A: Individual test } \\
\hline Austria & 1975 & $1.67 * * *$ & $(4.73)$ & 0.56 & $(1.29)$ & 0.62 & $(1.31)$ & 0.69 & $(1.46)$ \\
\hline Canada & 1975 & $0.97 * * *$ & $(3.41)$ & $1.16^{* * *}$ & $(3.27)$ & $1.38 * * *$ & $(4.02)$ & $1.37 * * *$ & $(4.00)$ \\
\hline Denmark & 1975 & $1.50 * * *$ & $(5.50)$ & $1.51 * * *$ & $(4.54)$ & $1.60 * * *$ & $(4.82)$ & $1.69 * * *$ & $(5.42)$ \\
\hline France & 1975 & $0.76^{* *}$ & $(2.66)$ & $0.59 * *$ & $(2.03)$ & $0.71 * *$ & $(2.46)$ & $0.75 * * *$ & $(2.61)$ \\
\hline Italy & 1975 & $1.97 * * *$ & $(3.51)$ & $1.31 * *$ & $(2.00)$ & $1.43 * *$ & $(2.13)$ & $1.55 * *$ & $(2.30)$ \\
\hline Netherlands & 1975 & $1.16^{* * *}$ & $(3.90)$ & $1.04 * * *$ & $(2.66)$ & $1.17 * * *$ & $(2.96)$ & $1.21 * * *$ & $(3.14)$ \\
\hline Norway & 1975 & $1.48 * * *$ & $(3.85)$ & $1.27 * * *$ & $(3.07)$ & $1.43 * * *$ & $(3.46)$ & $1.43 * * *$ & $(3.48)$ \\
\hline Spain & 1988 & $0.73 *$ & (1.90) & $0.78 *$ & (1.92) & $0.97 * *$ & $(2.41)$ & $1.14 * * *$ & $(2.87)$ \\
\hline Sweden & 1984 & $0.93 * *$ & $(2.10)$ & $0.94 *$ & (1.84) & $1.10 * *$ & $(2.21)$ & $1.16 * *$ & $(2.32)$ \\
\hline Switzerland & 1975 & $0.91 * * *$ & $(3.46)$ & $1.18 * * *$ & $(3.64)$ & $1.20 * * *$ & (3.64) & $1.22 * * *$ & $(3.71)$ \\
\hline \multirow[t]{2}{*}{ UK } & 1956 & $0.66^{* *}$ & $(2.39)$ & $0.55^{*}$ & $(1.77)$ & $0.75 * * *$ & $(2.57)$ & $0.84 * * *$ & $(2.97)$ \\
\hline & \multicolumn{9}{|c|}{ Time-series momentum } \\
\hline Europe & 1975 & $1.31 * * *$ & $(2.68)$ & 0.60 & $(0.98)$ & 0.72 & $(1.12)$ & 0.71 & $(1.03)$ \\
\hline North America & 1975 & $0.71 *$ & (1.68) & 0.65 & $(1.10)$ & $1.01 *$ & $(1.73)$ & $1.02 *$ & $(1.67)$ \\
\hline \multirow[t]{2}{*}{ All } & 1975 & $1.17 * *$ & $(2.44)$ & 0.43 & $(0.70)$ & 0.61 & $(1.01)$ & 0.68 & $(1.02)$ \\
\hline & \multicolumn{9}{|c|}{ Revised time-series momentum } \\
\hline Europe & 1975 & $2.08 * * *$ & $(3.94)$ & $1.17 * *$ & $(2.24)$ & $1.30 * *$ & $(2.45)$ & $1.49 * * *$ & $(2.75)$ \\
\hline North America & 1975 & $1.35^{* * *}$ & $(4.00)$ & $1.21 * * *$ & $(3.01)$ & $1.21 * * *$ & $(2.93)$ & $1.38 * * *$ & $(3.33)$ \\
\hline
\end{tabular}




\begin{tabular}{lllllccccc} 
All & 1975 & $1.87 * * *$ & $(4.20)$ & $1.17 * * *$ & $(2.64)$ & $1.27 * * *$ & $(2.81)$ & $1.54 * * *$ & $(3.33)$ \\
& & & & & Dual momentum & & & & \\
Europe & 1975 & $3.47 * *$ & $(2.27)$ & 3.33 & $(1.49)$ & $3.83 *$ & $(1.71)$ & $4.42 * *$ & $(1.97)$ \\
North America & 1975 & $1.61 * * *$ & $(2.86)$ & 1.12 & $(1.40)$ & $1.64 * *$ & $(2.27)$ & $1.96 * * *$ & $(2.70)$ \\
All & 1975 & $2.87 * * *$ & $(2.71)$ & $2.60^{*}$ & $(1.70)$ & $3.02 * *$ & $(2.01)$ & $3.60 * *$ & $(1.99)$ \\
\hline
\end{tabular}




\section{Online Appendix to "Time-Series Momentum in Nearly 100 Years of Stock Returns"}

\section{Table A1: Alternative formation and holding periods}

This table presents the average monthly TSMOM returns for alternative formation and holdingperiod combinations. All stocks are assigned to winner and loser groups based on the signs of their cumulative returns from $t-2$ to $t-J-1$, where $J$ equals $3,6,9$ and 12 . The resulting WML portfolios are held for $K$ months, where $K$ equals 3, 6, 9 and 12. There is a one-month gap between formation and holding. Panels $\mathrm{A}, \mathrm{B}$ and $\mathrm{C}$ present the monthly returns of the value-, volatility- and equal-weighted WML portfolios, respectively. $t$-values are reported between parentheses. Statistical significance at the $1 \%, 5 \%$ and $10 \%$ levels is denoted by ***,** and *, respectively.

\begin{tabular}{|c|c|c|c|c|}
\hline$K=$ & 3 & 6 & 9 & 12 \\
\hline \multicolumn{5}{|c|}{ Panel A: Value weighted } \\
\hline \multirow[t]{2}{*}{3} & 0.25 & $0.29 *$ & $0.35^{* *}$ & $0.28 * *$ \\
\hline & $(1.33)$ & $(1.85)$ & $(2.42)$ & $(2.10)$ \\
\hline \multirow[t]{2}{*}{6} & $0.45^{* *}$ & $0.56^{* * *}$ & $0.51 * * *$ & $0.41 * *$ \\
\hline & $(2.20)$ & $(2.83)$ & $(2.78)$ & $(2.42)$ \\
\hline \multirow[t]{2}{*}{9} & $0.68^{* * *}$ & $0.59 * * *$ & $0.52 * * *$ & $0.39 * *$ \\
\hline & $(3.14)$ & $(2.82)$ & $(2.62)$ & $(2.08)$ \\
\hline \multirow[t]{2}{*}{12} & $0.57 * *$ & $0.53 * *$ & $0.42 * *$ & 0.30 \\
\hline & $(2.54)$ & $(2.45)$ & $(1.99)$ & $(1.42)$ \\
\hline \multicolumn{5}{|c|}{ Panel B: Volatility weighted } \\
\hline \multirow[t]{2}{*}{3} & 0.30 & $0.32 * *$ & $0.36^{* *}$ & $0.29 * *$ \\
\hline & $(1.57)$ & $(2.02)$ & $(2.51)$ & $(2.20)$ \\
\hline \multirow[t]{2}{*}{6} & $0.51 * *$ & $0.59 * * *$ & $0.52 * * *$ & $0.41 * *$ \\
\hline & $(2.50)$ & $(3.10)$ & $(2.94)$ & $(2.52)$ \\
\hline \multirow[t]{2}{*}{9} & $0.71^{* * *}$ & $0.62 * * *$ & $0.52 * * *$ & $0.38 * *$ \\
\hline & $(3.33)$ & $(3.02)$ & $(2.71)$ & $(2.11)$ \\
\hline \multirow[t]{2}{*}{12} & $0.60 * * *$ & $0.52 * *$ & $0.39 *$ & 0.27 \\
\hline & $(2.67)$ & $(2.38)$ & $(1.86)$ & $(1.32)$ \\
\hline \multicolumn{5}{|c|}{ Panel C: Equal weighted } \\
\hline \multirow[t]{2}{*}{3} & 0.17 & 0.22 & 0.31 & 0.21 \\
\hline & $(0.64)$ & $(1.00)$ & $(1.59)$ & $(1.17)$ \\
\hline \multirow[t]{2}{*}{6} & 0.45 & $0.58 * *$ & $0.49 * *$ & 0.31 \\
\hline & $(1.54)$ & $(2.18)$ & $(1.99)$ & $(1.38)$ \\
\hline \multirow[t]{2}{*}{9} & $0.73 * *$ & $0.57 * *$ & 0.42 & 0.22 \\
\hline & $(2.45)$ & $(2.03)$ & $(1.61)$ & $(0.92)$ \\
\hline \multirow[t]{2}{*}{12} & $0.49 * * *$ & 0.36 & 0.20 & 0.03 \\
\hline & $(1.59)$ & $(1.22)$ & $(0.69)$ & $(0.09)$ \\
\hline
\end{tabular}




\section{Table A2: Subperiod Analysis}

The table reports the value-, volatility- and equal-weighted monthly returns of the time-series stock momentum (TSMOM) strategies in four subsample periods. Panel A presents the monthly returns of the TSMOM strategies across the year; Panel B reports the average monthly returns in January alone and from February to December, for the TSMOM strategies. The sample period is from January 1927 to September 2017.

\begin{tabular}{|c|c|c|c|c|}
\hline \multicolumn{5}{|c|}{ Panel A: Time-series momentum sub-period analysis } \\
\hline & 1927-1949 & $1950-1972$ & $1973-1995$ & $1996-2017$ \\
\hline Value & 1.02 & $0.88 * * *$ & $0.58^{*}$ & $0.55^{*}$ \\
\hline Weighted & $(1.40)$ & $(3.13)$ & $(1.76)$ & $(1.76)$ \\
\hline Volatility & 0.99 & $0.88 * * *$ & $0.83 * * *$ & $0.49 *$ \\
\hline weighted & $(1.32)$ & $(3.12)$ & $(2.97)$ & $(1.71)$ \\
\hline Equal & 1.00 & $1.11 * * *$ & $0.92 * *$ & 0.37 \\
\hline Weighted & $(0.98)$ & $(3.16)$ & $(2.30)$ & $(0.89)$ \\
\hline \multicolumn{5}{|c|}{ Panel B: January vs. Non-January } \\
\hline & $1927-1949$ & $1950-1972$ & $1973-1995$ & $1996-2017$ \\
\hline \multicolumn{5}{|c|}{ Value weighted } \\
\hline \multirow[t]{2}{*}{ January } & 1.28 & -1.48 & -0.92 & -0.31 \\
\hline & $(0.93)$ & $(-1.36)$ & $(-0.57)$ & $(-0.24)$ \\
\hline \multirow[t]{3}{*}{ Feb-Dec } & 1.00 & $1.10^{* * *}$ & $0.72 * *$ & $0.63 * *$ \\
\hline & $(1.27)$ & $(3.80)$ & $(2.17)$ & $(1.95)$ \\
\hline & \multicolumn{4}{|c|}{ Volatility weighted } \\
\hline \multirow[t]{2}{*}{ January } & 0.89 & -1.63 & -1.21 & -0.60 \\
\hline & $(0.45)$ & $(-1.23)$ & $(-0.67)$ & $(-0.59)$ \\
\hline \multirow[t]{2}{*}{ Feb-Dec } & 1.00 & $1.08 * * *$ & $1.01 * * *$ & $0.59 * *$ \\
\hline & $(1.25)$ & $(4.00)$ & $(3.99)$ & $(1.98)$ \\
\hline \multicolumn{5}{|c|}{ Equal weighted } \\
\hline \multirow[t]{2}{*}{ January } & 1.15 & -2.28 & -2.89 & -2.43 \\
\hline & $(0.35)$ & $(-1.31)$ & $(-1.00)$ & $(-1.19)$ \\
\hline \multirow[t]{2}{*}{ Feb-Dec } & 1.00 & $1.42 * * *$ & $1.26^{* * * *}$ & 0.63 \\
\hline & $(0.92)$ & $(4.13)$ & $(3.68)$ & $(1.53)$ \\
\hline
\end{tabular}

